
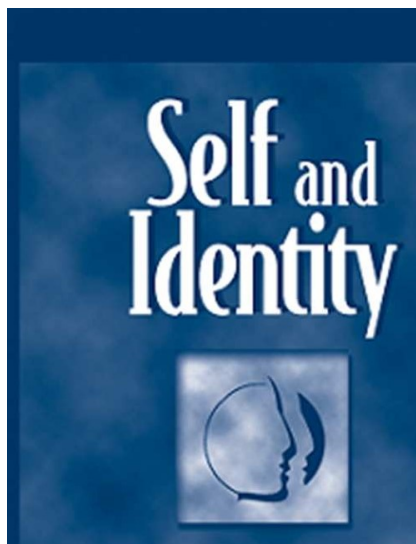

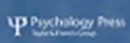

\title{
Self-Affirmation and an incongruent drinking norm: Alcohol AbusePrevention Messages Targeting Young People
}

\begin{tabular}{|r|l|}
\hline Journal: & Self and Identity \\
\hline Manuscript ID: & SAI 31.15 \\
\hline Manuscript Type: & Regular Article \\
\hline Date Submitted by the Author: & $28-$-Feb-2015 \\
\hline Keymote List of Authors: & $\begin{array}{l}\text { Voisin, Dimitri; University of Reims Champagne-Ardenne, Psychology } \\
\text { Girandola, Fabien; Aix-Marseille University, Psychology } \\
\text { David, Mathieu; University of Reunion, Psychology } \\
\text { Aim, Marie-Anastasie; Aix-Marseille University, Psychology }\end{array}$ \\
\cline { 2 - 2 } & self-affirmation, deviance, descriptive norm, discrediting \\
\hline
\end{tabular}

\section{SCHOLARONE \\ Manuscripts}


Running head: SELF-AFFIRMATION AND ALCOHOL

Self-Affirmation and an incongruent drinking norm: Alcohol Abuse Prevention Messages

Targeting Young People

Dimitri Voisin

University of Reims, Reims, France

Fabien Girandola

LPS EA 849, Aix Marseille University,

Aix en Provence, France

\author{
Mathieu David \\ University of Reunion, Saint Denis, France \\ Marie-Anastasie Aim \\ LPS EA 849, Aix Marseille University, \\ Aix-en-Provence, France
}

February 27th, 2015

Word count:

Abstract: 146

Manuscrit: 13,001

Correspondence should be sent to Dimitri Voisin, Université de Reims, Laboratoire

C2S, 57 avenue Taittinger, 51096 Reims Cedex, France; email: dimitri.voisin@univ-reims.fr;

telephone number: +33 326913797

URL: http://mc.manuscriptcentral.com/psai Email: reviews@psypress.co.uk 


\begin{abstract}
Many health campaigns are designed to reduce dangerous binge drinking and challenge misperceptions of the prevailing drinking norm. For drinkers, this situation is problematic. Information about health risks and statements that only a few people binge drink (low descriptive norm) threaten their self-integrity, so to combat this self-threat and preserve their positive self-integrity, drinkers discredit the message as a coping strategy. Research suggests that this discrediting strategy could be countered with a self-affirmation procedure. In the present study, we attempted to demonstrate the beneficial effects of self-affirmation, and measure just how far it can protect self-integrity. Across three experiments, we found that self-affirmation does indeed reduce discrediting, but only providing there is no normative information in the health message. Individuals prefer the discrediting strategy to selfaffirmation when they are told that few people binge drink among their age group. The theoretical implications for self-affirmation are discussed.
\end{abstract}

Keywords: self-affirmation, descriptive norm, deviance, discrediting 


\title{
Self-Affirmation and a Low Drinking Norm: Alcohol Abuse Prevention Messages Targeting Young People
}

\begin{abstract}
Across Western countries, binge drinking is a widespread social trend among students and other young people ${ }^{1}$. In an attempt to change inappropriate behaviors and attitudes in relation to health, national campaigns related to alcohol intake have sought to warn individuals about the dangers of excessive drinking. However, simply informing the public about the dangers of certain health-related behaviors seems to have very little impact on cognitions and/or behaviors (Harris \& Epton, 2009). Instead of considering the message content and changing their cognitions and/or behavior in line with recommendations, individuals may engage in a defensive process.
\end{abstract}

\section{Threatening Self-Integrity with a Health Message}

The present study adopted the approach advocated by self-affirmation theory (Aronson, Cohen, \& Nail, 1999; Sherman \& Cohen, 2006; Steele, 1999). Because they threaten self-integrity, persuasive messages may ironically trigger a coping strategy. Informing individuals that their alcohol-related behaviors are bad habits and cause negative health outcomes can trigger a self-serving bias (Kunda, 1987; Liberman \& Chaiken, 1992). People may discredit the message's conclusion to preserve their self-integrity. Individuals are deeply motivated to maintain an overall positive and coherent self-perception "as having adaptive and moral adequacy, as being competent, good, stable, integrated, capable of choice and control, and so forth" (Steele, 1999, p. 386). Telling them that their behaviors are risky may suggest that they are reckless with their health (Sherman \& Cohen, 2002, 2006), which runs counter to their positive self-integrity. If they admit that they have engaged in inappropriate behaviors that are in contradiction with their desire for good health, this inconsistency creates a threat to their self-integrity. The message becomes threatening and highlights the unsuitable nature of their bad habits pertaining to alcohol consumption. Faced 
with any sort of self-threat, people spontaneously seek to resolve the conflict (Major \& O'Brien, 2005). Therefore, to protect their self-integrity, they adopt a coping strategy that consists in denying or discrediting the message. As a result, they cease to perceive the discrepancy, insofar as they no longer have any reason to believe that their past behaviors (i.e., alcohol-related habits) pose a threat to their health. In other words, the self-defense mechanism enables them to protect their self-integrity, and they continue to perceive themselves as coherent and adaptive.

Research on biased information processing following a persuasive message has tended to focus on the link between behaviors and the stated negative outcomes. From another perspective, however, drinking behavior is deeply embedded in social relations and social norms during adolescence and early adulthood. Young people mostly drink alcohol at parties with their peers. One of the most predictive factors for drinking alcohol is social norm (Neighbors, Lee, Lewis, Fossos, \& Larimer, 2007; Piane \& Safer, 2008). Young people's drinking behavior reflects their obedience to perceived peer pressure. Heath messages may therefore call prevailing social norms into question. The binge drinking social norm can be regarded as maladaptive. In other words, the social norm is harmful because it encourages individuals to engage in hazardous acts. According to social identity theory (Tajfel \& Turner, 1979, 1986), the self-concept is formed along a personal-social continuum. Belonging to a group means espousing its social norms, which are included in the self-concept. A health message may threaten self-integrity if it reveals the maladaptive aspect of the corresponding social norm. As young people tend to drink alcohol to conform to a social norm, rather than to satisfy from personal desire, their drinking behavior reflects compliance with a drinking norm. Statistically, therefore, their drinking behavior should predict message acceptance because the alcohol consumption measure is a confounding variable (see, MacKinnon, Krull, \& Lockwood, 2000, for a definition) with the subjective norm. 


\section{Deviance Constitutes a Threat to Self-Integrity}

This analysis of the low impact of health prevention messages has led many researchers (Borsari \& Carey, 2008; Dieterich, Stanley, Swaim, \& Beauvais, 2013; Moreira, Smith, \& Foxcroft, 2010; Perkins, Linkenbach, Lewis, \& Neighbors, 2010) to look for strategies for improving the impact of these messages and triggering change, in particular the use of descriptive norms (Cialdini, 2007). This strategy consists in telling the public what most people do in particular contexts. However, there may be a discrepancy between what a health campaign says and what individuals think. For example, the stated drinking norm may be lower than young people think it is. This misperception is rooted in a perceived norm of heavy drinking that encourages young people to binge drink (Corbin, Iwamoto, \& Fromme, 2011; Neighbors et al., 2007; Page, Ihasz, Hantiu, Simonek, \& Klarova, 2008; Piane \& Safer, 2008). In other words, young people drink heavily because they generally overestimate the number of other young people who drink heavily at parties. Given this observation, it is tempting to provide an explicit descriptive norm that is lower than the perceived norm, as a means of changing inappropriate attitudes and behaviors. This intervention supposedly overcomes young people's misperceptions and lead to healthier behaviors. Although the provision of descriptive norms has become a popular technique for changing cognitions and behaviors (Cialdini, 2007; Cialdini et al., 2006; Cialdini, Reno, \& Kallgren, 1990; Kallgren, Reno, \& Cialdini, 2000; Reno, Cialdini, \& Kallgren, 1993; Schultz, Nolan, Cialdini, Goldstein, \& Griskevicius, 2007), some analyses indicate that the influence of descriptive norms in prevention messages is somewhat mixed (Blanton, Köblitz, \& McCaul, 2008; Lewis \& Neighbors, 2006; Wechsler et al., 2003). A descriptive norm has an effect on attitudes and behaviors when it is congruent with what people think of the social norm at issue (Cialdini, 2003). If, however, the stated descriptive norm does not match what people think they know about the social norm (subjective norm), which is often the situation in health messages, the 
descriptive norm has only a weak effect on cognitive and behavioral changes. Even so, the absence of change in the wake of information about a general descriptive norm does not mean that these general descriptive norms have no impact whatsoever on individuals.

In terms of self-affirmation theory (Sherman, 2013), information about a low descriptive norm may also be interpreted as a threat to self-integrity. Telling individuals about the percentage of people who are accustomed to drinking heavily enables them to compare their own behaviors with that descriptive norm. Trying to decrease the misperception of a massive binge drinking norm by contrasting it with a real- or bogus-descriptive norm (e.g., only a very small number of people are heavy drinkers) emphasizes the deviant nature of binge drinking (i.e., the discrepancy between the group norm and the individual's drinking behavior). People can, however, come to view themselves as deviants in relation to a descriptive norm set out in a health message. In other words, if they conclude that they belong to a minority (i.e., behaving discrepantly vis-à-vis the stated descriptive norm), they may feel they are in the extremely uncomfortable position of deviants (Christensen, Rothgerber, Wood, \& Matz, 2004). Descriptive norms are influential because individuals seek to avoid being ostracized and becoming a black sheep (Marques \& Yzerbyt, 1988). Deviant individuals threaten the group's cohesiveness and distinctiveness (Wellen \& Neale, 2006). According to Abrams and colleagues, “[...] deviants are evaluated negatively because they undermine valued group norms, and not just because they are dissimilar from the group per se" (2002, p. 172).

One particular function of groups is to enable people to predict how the members of a given group will behave and think. The social environment is then perceived of as more controllable and therefore less uncertain (Hogg \& Reid, 2006). Announcing a norm that is incongruent with what individuals hitherto thought about their group represents a sudden normative change. This situation "can produce an acute sense of identity threat and self- 
conceptual uncertainty, impermanence, and instability” (Hogg \& Reid, 2006, p. 22). They

realize that they are unable to predict and understand the other in-group members' behaviors.

Being confronted with a health message that contains an incongruent descriptive norm (compared with the perceived norm) therefore emphasizes the deviance of their behavior in relation to the majority and their mismatch with their peers. According to Cialidini and Trost (1998), people are motivated to respect descriptive norms because they "maximize the effectiveness of their social behavior" (p. 155) and allow them to attain goals. In other words, announcing an incongruent descriptive norm signals to people that their social behavior is ineffectual and they are out of line with their group. When they are no longer capable of predicting the social norm, people lose control of their social environment (Cialdini \& Trost, 1998). Ultimately, the announcement of an unexpectedly low descriptive norm forces people to compare their behavior with that of others, and is therefore a threat to their self-integrity. In addition to threatening self-integrity, the announcement of a low drinking norm can activate people's identity as drinkers. According to self-categorization theory (Turner, Hogg, Oakes, Reicher, \& Wetherell, 1987), identity has several different facets. Furthermore, individuals conform to different group prototypes according to the facet of their identity that is made salient by the context. Normative information about alcohol consumption therefore forces people to compare their habitual drinking behaviors with the stated descriptive norm. This information is so inextricably bound up with group (Hogg \& Reid, 2006) that it can activate the drinker identity, causing people to interpret the health message as drinkers. Obviously, a message emphasizing the harmful effects of binge drinking will threaten this drinker identity, and people may once again seek to protect their self-integrity by discrediting the health message (Kunda, 1987; Liberman \& Chaiken, 1992), finding fault with the arguments it puts forward. According to this analysis, the extent to which individuals discredit 
the health message in order to protect their drinker identity will depend on their habitual drinking behaviors.

\section{Self-Affirmation}

When faced with threats to the self (e.g., health messages for people with unhealthy behaviors), individuals have to resort to some sort of coping strategy. Discrediting the message is not the only way of protecting one's self-integrity. Another self-defense mechanism consists in affirming an important feature of one's self-concept (Creswell et al., 2007; see McQueen \& Klein, 2006, for a review; Reed \& Aspinwall, 1998; Sherman \& Cohen, 2002, 2006; Sherman \& Hartson, 2011; Sherman, Nelson, \& Steele, 2000). Researchers have used several methods to encourage participants to affirm features of their self-concepts. In the present study, we focused on two procedures.

The first procedure is attribute affirmation, where the goal is to make a personal attribute more salient. People are given bogus positive feedback in the form of a label such as you are creative (Aronson, Blanton, \& Cooper, 1995; Blanton, Cooper, Slkurnik, \& Aronson, 1997; Spencer, Fein, \& Lomore, 2001). This label is made credible by first getting the participants to fill out a personality questionnaire. This feedback is an efficient way of shielding the self-concept from a threat. For example, in Aronson and colleagues'(1995) study, participants experiencing cognitive dissonance did not need to change their attitude (reduction mode) to preserve a feeling of consistency. The second procedure is value affirmation (Sherman et al., 2000). This has the identical goal of making a central and important value salient, but does so by getting participants to rank ten or eleven values (e.g., creativity, relations with friends/family, etc.), then explain and give examples of why the top value is important in daily life.

When individuals have been self-affirmed by one of these methods prior to exposure to a self-threat, they no longer need to use a spontaneous coping strategy (e.g., denying a 
message's findings) to protect their self-integrity. Instead, they end up accepting and acknowledging arguments as being true without trivializing them (Correll, Spencer, \& Zanna, 2004; Jessop, Simmonds, \& Sparks, 2009). Many studies have shown that people accept message conclusions if their self-concept has been affirmed (Armitage, Harris, \& Arden, 2011; Armitage, Harris, Hepton, \& Napper, 2008; Epton \& Harris, 2008; Griffin \& Harris, 2011; Harris \& Epton, 2009; Harris \& Napper, 2005; Harris, 2011; Klein et al., 2010; Sherman et al., 2000; van Koningsbruggen, Das, \& Roskos-Ewoldsen, 2009).

The different facets of identity include roles, groups, and elements that can be affirmed in the attribute- and value-affirmation procedures. The self-affirmation process therefore involves activating a positive and important element of identity. According to Sherman (2013), this affirmation has three major implications for managing a self-threat: 1) self-affirmation provides self-resources to people; 2) with these affirmational resources at their disposal, they are able to perceive the threatening information from a broader perspective; and 3) the self-threat relationship is uncoupled. People regard the threat as irrelevant to their self-evaluation.

\section{Present Study}

The present study was in line with research on the relationship between behaviors and health message acceptance (Kunda, 1987; Liberman \& Chaiken, 1992). More specifically, we sought to ascertain whether self-affirmation constitutes a means of disrupting the behavior-acceptance relationship. The protection afforded by self-affirmation against threats to self-integrity in the field of health prevention has already been well documented (Cohen \& Sherman, 2014; Harris \& Epton, 2009; Harris, 2011; Sherman \& Cohen, 2006; Sherman et al., 2000), including for drinking behavior (Armitage et al., 2011; Ferrer, Shmueli, Bergman, Harris, \& Klein, 2011; Harris \& Napper, 2005; Klein, Harris, Ferrer, \& Zajac, 2011; Klein \& Harris, 2009; Scott, Brown, Phair, Westland, \& Schüz, 2013). Research has shown that self- 
affirmation can uncouple the link between behavior and acceptance (Cohen \& Sherman, 2014; Harris \& Epton, 2009). Moreover, self-affirmation is acknowledged to be a viable strategy for shielding self-integrity from self- and group threats to (for a review, see Sherman \& Cohen, 2006; Sherman \& Hartson, 2011).

Research so far has focused on the effects of self-affirmation when people are confronted with a health-related message. Our review of normative information in health messages revealed that people actually need to manage two threats to their self-integrity: one arising from the discrepancy between their desire for good health and their drinking habits (self-threat); the other arising from their failure to respect the ingroup descriptive norm (group-threat). We therefore sought to improve current understanding of the effects of selfaffirmation on the acceptance of health messages as a function of drinking behavior in the presence of a double threat to self-integrity: a heightened group threat and the undermining of self-integrity by drinking behaviors.

By generating two threats to self-integrity, the present study was able to test the limitations of self-affirmation as a buffer to threats. Most studies have attempted to list the conditions needed to implement a self-affirmation procedure in order to protect self-integrity, and some have identified possible limitations. First, individuals have to be unaware of its beneficial effects (Sherman et al., 2009). Second, the content of the affirmation must be irrelevant to the threat (Blanton et al., 1997; Sivanathan, Molden, Galinsky, \& Ku, 2008). Third, a recent article (Shapiro, Williams, \& Hambarchyan, 2013) showed that the efficacy of self-affirmation in reducing the negative impact of stereotype threat on performance depends on the target of that threat (self-as-target vs. group-as-target). Self-affirmation was found not to be an effective buffer in the group-threat condition. In some group threats, there may also be a risk of exclusion owing to the deviance of behaviors. Prewitt-Freilino and Bosson (2008) showed that self-affirmation failed to restore a sense of self-integrity because the threat was 
accompanied by a risk of interpersonal punishments following counternormative behavior.

Whether or not self-integrity is restored, the consequence of deviance remains. Self-

affirmation cannot, therefore, cope with both outcomes of the threat (self-integrity plus

exclusion). If the self-affirmation procedure is not entirely appropriate for buffering the threat, individuals have to cope with that threat some other way.

Prewitt-Freilino and Bosson (2008) and Shapiro and her colleagues (2013) suggested testing the efficacy of self-affirmation with different types of threat (self- vs. group-threat). We therefore looked at just how far self-affirmation can preserve positive self-integrity and uncouple the behavior-acceptance relationship. Can self-affirmation shield self-integrity from any type of threat? Classically, the more alcohol young people are accustomed to drinking, the more they resort to discrediting the message to protect their self-concept when confronted with threatening information (Harris \& Epton, 2009). However, if they are given an opportunity to self-affirm (whatever their habitual alcohol intake), they accept the conclusion of the health message (i.e., no discrediting) because their self-integrity is protected (Harris \& Napper, 2005). In line with Prewitt-Freilino and Bosson (2008), we can assume that if identity is threatened by emphasizing the deviance of binge drinking, then self-affirmation will not protect self-integrity. Individuals will keep on discrediting the message as a coping strategy, even if they were previously self-affirmed. Thus, we would expect the level of message acceptance to depend on people's alcohol-related habits, with heavy drinkers being less inclined to accept the health message than people who drink very little.

There are two reasons why self-affirmation may not be a viable defensive strategy when people are confronted with information that threatens their self-integrity, plus a norm that emphasizes their deviance:

1) The self-concept is made up of different elements including personality traits, attributes, roles and group membership. Self-affirmation acts as a buffer against self-threats 
because a positive and important element of this self-concept (e.g., attribute or value) is activated. The announcement of a low drinking norm may activate another element of the self-concept (here, drinker group membership). The drinker identity is thus activated and associated with a stigmatized minority. The descriptive norm highlights the negative and maladaptive aspect of belonging to the drinker group. The self-affirmation induced by a procedure prior to exposure to the threat may thus be associated with the drinker identity. If both identity elements (positive and negative) are made salient, they may well come into conflict with each other, interfering with the affirmation process. The activation of two identity elements may therefore reduce access to the general self-concept, depriving individuals of self-affirmational resources;

2) Emphasizing the deviance of a behavior brings with it a risk of stigmatization and rejection by others. The individuals concerned have no control over the others. The associated risk cannot be managed by self-affirmation (Prewitt-Freilino \& Bosson, 2008), and discrediting the message seems a more effective coping strategy. If the message is perceived of as unbelievable or unreliable, then all the information it contains must be worthless. This is a way of decreasing the perceived risk of rejection by others.

In summary, we hypothesized that reading a threatening health-related message that does not contain any normative information induces a coping strategy in those individuals concerned by the message's content. The more alcohol people drink, the more they will deny the message's conclusions (Hypothesis 1). If individuals are given an opportunity to selfaffirm prior to being exposed to the prevention message, their self-integrity will be protected, thus rendering the defensive bias pointless. Self-affirmation therefore diminishes or uncouples the link between alcoholic behavior and message acceptance (Hypothesis 2). If the message includes information pointing to a low descriptive drinking norm, this generates a groupthreat among the heaviest drinkers and activates their drinker identity. As we argued above, in 
this situation they will use discrediting as a coping strategy and will not draw on their selfaffirmational resources (Hypothesis 3).

\section{Overview}

We conducted three experiments to test the effect of self-affirmation on the relationship between habitual drinking behaviors and general acceptance of health messages, in the presence or absence of normative information concerning the small number of binge drinkers among adolescents and students. We tested our hypotheses using attribute affirmation (Experiment 1) and value affirmation (Experiments 2 and 3) as self-affirmation procedures. Given that the content of self-affirmation must be irrelevant to the self-threat so that acceptance is uncoupled from the alcohol-related behavior, we expected to observe an exacerbation of discrediting (the negative relationship between the alcohol consumption and acceptance) when individuals affirmed an important group value (group affirmation) and learned about a low drinking norm (Experiment 2). Finally, we sought to assess the selfaffirmation effect whether the threat to self-integrity stemmed either from the health message or from deviance. To this end, we measured the subjective norm and drinking behaviors as predictors of health message acceptance (Experiment 3).

\section{Pilot study}

The pilot study had two goals. First, we needed to check whether the different measures of alcohol consumption we used were related to binge drinking. Second, we needed to show that alcohol consumption is related to the perception of a social norm. We asked 202 students aged $18-25$ years $\left(120\right.$ women, $\left.M_{\text {age }}=21.27, S D_{\text {age }}=1.91\right)$ from Aix-en-Provence (France) about the subjective norm (three items, e.g., "If I binge drink in a single session within the next two weeks most people who are important to me will (1) approve or (7) disapprove; Cronbach's $\alpha=.86$ ) and the group norm (four items, e.g., "How much would your friends and peers at university agree that binge drinking in a single session within the 
next two weeks is a good thing to do?"; Cronbach's $\alpha=.90)$. Both these scales were adapted from Johnston and White (2003). We then measured the descriptive norm by asking how many drinks a typical student consumes when he or she "goes to a bar", "has friends over to his or her flat for drinks", or "goes to a party" (Rimal \& Real, 2005). Finally, participants completed six items on their alcohol consumption related to states of drunkenness ([1] "How many times were you drunk in the previous month?" and [2] "How many times are you drunk on average in a normal month?"), drinking habits ([3] "How much alcohol did you drink in the previous seven days?" and [4] "How much do you drink on average in a normal week [number of glasses/drinks]?”) and intake at parties ([5] "Usually, during a party, how many alcoholic drinks do you consume on average?" and [6] "During a party with friends, how much alcohol do you drink?" [number of glasses/drinks]). A principal component analysis (PCA) on alcohol-related items yielded only one factor (eigenvalue $>1$ ), which explained $64.90 \%$ of variance, after it had been checked with the Kaiser-Meyer-Olkin (0.76) measure of sampling adequacy, and Bartlett's test of sphericity, $\chi^{2}(15)=822.98, p<.001$, the two conditions of application. All items loaded onto the factor $(>.70)$. From this PCA, we extracted a factor score for each participant. As already observed in a French sample (Richard, Spilka, \& Beck, 2013), women reported drinking less than men, $t(194)=-3.38, p=$ .001. Moreover, alcohol intake was correlated with the subjective norm $(r=.44, p<.001)$, group norm $(r=.39, p<.001)$ and descriptive norm $(r=.50, p<.001)$. These results indicated that, for the purposes of the subsequent experiments, the more alcohol young people drank, the more the announcement of a low drinking norm would create a perception of discrepancy. The discrepancy between what they thought was the social norm and the social norm announced by the health message would be especially great because they were accustomed to drinking at parties and in their daily lives. 
Participants were also requested with a single item whether they had already experienced binge drinking $(1=$ Never, $2=$ Once, $3=$ Several times and $4=$ Every week $)$. Binge drinking was defined in the item as being an extreme state of drunkenness ("stoned") reached in a very short interval. This item was significantly correlated (Spearman's $\rho$ ) with subjective norm, group norm and descriptive norm (respectively, $\rho=.39, \rho=.26$ and $\rho=.21$, all $p \mathrm{~s} \leq .003$ ). Importantly for the measures of alcohol intake in the subsequent three experiments, each alcohol-related item was correlated with the others. This means that each measure of alcohol intake predicted binge drinking among a sample of students and other young people (17-25 years old). Moreover, there was a correlation between the index of alcohol intake and the self-reported item on binge drinking, $\rho=.37, p<.001$. In other words, the more alcohol they reported on any of these items, the more likely they were to identify themselves as binge drinkers. This is very important, as it meant that the indices we computed with these items would be related to binge drinking. The higher the alcohol intake index, the more threatened people would be by a health message mentioning the hazards of binge drinking.

\section{Experiment 1}

We tested the relationship between drinking behavior and acceptance of the health message as a function of normative information and self-affirmation by an attribute. An attribute can affirm the self-concept and thus restore self-integrity (McQueen \& Klein, 2006). However, it must be unrelated to the domain of the self-threat (Blanton et al., 1997; McCrea \& Hirt, 2011). For example, when Blanton and colleagues (1997) gave participants an opportunity to affirm compassion, even though they had shown that they lacked compassion in written statements about disabled people, it increased their cognitive dissonance, unlike the affirmation of creativity (attribute unrelated to the self-threat). We chose to use the creativity 
SELF-AFFIRMATION AND ALCOHOL

label to self-affirm participants so that there was no relationship between self-threat and attribute affirmation.

\section{Method}

Population and experimental design. A total of 228 students (156 women), aged $15-25$ years $\left(M_{\text {age }}=19.99\right.$ years, $\left.S D_{\text {age }}=1.93\right)$, from various French universities volunteered to take part in an online psychology study. They were invited by email to click on a web link to participate. They were randomly assigned to one of four experimental conditions in a 2 (creativity labeling vs. no labeling) $\times 2$ (low drinking norm vs. no normative information) between-participants factorial design.

Step 1: Attribute affirmation. All participants began by filling out a 44-item personality test in which they indicated the extent to which different traits corresponded to the way they perceived themselves (e.g., interested in art, sociable, shy). Upon completion of this questionnaire, participants were self-affirmed by receiving bogus feedback on their creativity (Aronson et al., 1995; Sivanathan et al., 2008). Participants' test results read "Your personality is characterized by strong creativity, which means you are able to demonstrate originality and imagination". In the no labeling condition (no self-affirmation), participants went directly to the next step without receiving any feedback.

Step 2: Threatening information and social norm. Next, participants read a text about the risks of brain damage after binge drinking (see Appendix 1). To be sure that everyone understood the article, it was preceded by the following definition of the term binge drinking: "quickly drinking large amounts of alcohol within a short space of time to quickly reach an intoxicated state". Participants in the low-drinking norm condition were told that "In Western countries, it is a practice that $17 \%$ of adolescents and students (young people aged between 15 and 24 years old) have experienced at least once in their lives". In the no normative information condition, the latter sentence was not provided. They then read the 
article on binge drinking at their own pace. The article reported the findings of two scientific studies indicating the harmful effects of binge drinking on the brain.

Step 3: Form completion. Participants next completed two message acceptance items adapted from Sherman, Nelson, and Steele (2000). They rated the question "To what extent do you think that binge drinking causes neurological damage to the brain?" on a scale ranging from 1 (Strongly disagree) to 9 (Strongly agree), and the question "To what extent do you think it is important that students stop binge drinking at parties with their friends?" on a scale ranging from 1 (Not at all important) to 9 (Extremely important), $r=.35, p<.001$. They were then asked to report their alcohol consumption. As the Alcohol Use Questionnaire widely used in studies of binge drinking (e.g., Townshend \& Duka, 2002), includes measures of both regular intake and drunkenness, we selected three items from the pilot study ("How many times were you drunk in the previous month?", "How much alcohol did you drink in the previous seven days [number of glasses/drinks]?" and "During a normal week, how much alcohol do you drink on average [number of glasses/drinks]?”; Cronbach's $\alpha=.76$ ). These three items were centered and reduced ( $z$ scores) to create a scale of alcohol intake. Finally, participants were directly requested to report whether they had already experienced binge drinking (see item in the pilot test).

\section{Results}

Manipulation checks. Alcohol consumption was always measured after the message acceptance variable, to avoid giving salience to drinking habits. We ran a 2 (self-affirmed vs. no affirmation $) \times 2$ (normative information vs. no normative information) analysis of variance (ANOVA) to determine whether the experimental conditions had any effect on the selfreported alcohol consumption measure. There was no main effect of attribute affirmation or normative information, and no interaction effect, on self-reported alcohol consumption (all $F \mathrm{~s}$ $<1)$. Scores on the self-report scale were therefore not influenced by the experimental 
conditions, and we used them as a predictor in the ensuing analyses. Moreover, the index of alcohol consumption was correlated with self-reported binge drinking, $\rho=.41, p<.001$.

Message acceptance. We used linear regressions (Aiken \& West, 1991) to assess the main and interaction effects of normative information, attribute affirmation and drinking habits on health message acceptance. All the independent variables were centered (attribute affirmation: $-1=$ no feedback and $1=$ creative; normative information: $-1=$ no normative information and $1=$ low drinking norm). All the factors and interaction terms were entered step by step in a hierarchical multiple regression. The covariates (age and sex) were entered in the first step. The main effects of alcohol consumption, normative information and attribute affirmation were tested in the second step. The third and fourth steps tested the two-way and three-way interactions, respectively.

First, whatever the experimental condition, results revealed an effect of alcohol consumption on health message acceptance. The more alcohol participants were accustomed to drinking, the less they accepted the message's conclusions, $\beta=-.36, t(222)=-5.82, p<$ .001 (Hypothesis 1).

Analysis also revealed an effect of the three-way interaction between the alcohol consumption, self-affirmation and normative information variables on message acceptance, $\beta$ $=-.16, t(218)=-1.98, p=.049$. In order to break this three-way interaction down, we looked for the interaction effects between alcohol consumption and attribute affirmation on acceptance in the no normative information and low binge-drinking norm conditions (see Fig. 1). In other words, we looked at whether the slopes differed significantly between the no feedback and creative conditions.

In the no normative information condition, a linear regression with interaction effects showed that alcohol consumption differently predicted message acceptance according to whether or not participants had been labeled as creative (slightly significant interaction effect 
between alcohol consumption and attribute affirmation), $\beta=-.19, t(105)=1.89, p=.059$ (see

Fig.1, top): participants discredited the health message less in the attribute-affirmation condition (i.e., creativity labeling), $\beta=-.28, t(50)=-2.08, p=.043$, than in the no attributeaffirmation condition, $\beta=-.43 t(55)=-3.51, p=.001$ (Hypothesis 2). By contrast, in the low drinking norm $(17 \%)$ condition, there was no significant difference in health message acceptance between participants in the attribute-affirmation and no self-affirmation conditions (no interaction effect), $\beta=-.14, t(115)=-1.23, p=.222$ (see Fig.1, bottom). Participants exhibited identical acceptance of the effects of alcohol on the brain in the attributeaffirmation, $\beta=-.50, t(63)=-4.58, p<.001$, and no self-affirmation, $\beta=-.39, t(52)=-3.01, p$ $<.001$, conditions (Hypothesis 3 ).

\section{Discussion}

The results of this first experiment supported our assumptions. The affirmation of an attribute unrelated to self only reduced the defensive bias (i.e., discrediting) when participants did not have explicit knowledge of the drinking norm. These initial results replicate those obtained by affirming kindness in the healthcare field (Reed \& Aspinwall, 1998), and further support the notion that labeling (here, creativity) is a viable way of affirming the self-concept (Aronson et al., 1995; Blanton et al., 1997; Sivanathan et al., 2008). However, if the low drinking norm was given salience and did not confirm drinkers' past behaviors, attribute affirmation had no effect on the relationship between health message acceptance and alcohol consumption. Participants continued to discredit the message about the effects of binge drinking on the brain. This suggests that the choice between self-affirmation strategy and discrediting as a coping strategy depends on the social descriptive norm. In the presence of the latter, individuals prefer to defend their self-integrity through discrediting, as this coping strategy is more efficient. 


\section{Experiment 2}

This second experiment had a twofold aim. First, according to Sherman and Cohen (2006), self-affirmation is only effective if the attribute or value is important to the individual concerned. In our case, we had doubts about the importance of creativity, and as we did not measure it, we have no way of knowing whether it varied across participants. For this reason, we decided to repeat our first experiment, but with a modified self-affirmation procedure. In Experiment 2, we opted for the value-affirmation procedure (Sherman et al., 2000), which controls the importance of the value used to self-affirm. Instead of imposing a self-attribute on participants, they were asked to select the most important value from different suggested alternatives, and then explain why it was important to them.

Our second aim was to test the hypothesis that highlighting individuals' deviant behavior through the announcement of a low drinking norm (i.e., only 17\% young people have experienced binge drinking) can arouse group-concerns. For this reason, alongside the value-affirmation procedure, we used a group-affirmation procedure in this second experiment (Glasford, Dovidio, \& Pratto, 2009; Gunn \& Wilson, 2011; Sherman, Kinias, Major, Kim, \& Prenovost, 2007). This method makes it possible to affirm the collective self (i.e., group-related self), as opposed to the personal self. To demonstrate that providing a low descriptive binge-drinking norm arouses group concerns, we exploited the limitations of selfaffirmation. Associating a relevant attribute with the threat increases that threat instead of diminishing it (Blanton et al., 1997). Assuming that a low descriptive norm condition induces group concerns, affirming important values related to the individual's group would be relevant to that threat. This would further increase concerns, and discrediting would therefore be preferred to self-affirmation. In Aronson and colleagues' study (1995), the relevant attribute not only did not decrease the dissonance state, but actually exacerbated it. Thus, 
group affirmation might intensify discrediting as a coping strategy in the low descriptive norm condition.

In spite of recurrent results showing that group affirmation shields positive selfintegrity from threats, we hypothesized that group affirmation does not reduce discrediting. Affirming an important group value is a way of priming aspects of the public self. It also primes social norms (Brewer \& Gardner, 1996), which people tend to enforce. Given that young people believe that there is a massive binge-drinking norm, we reasoned that the groupaffirmation procedure would activate this prevailing norm, and the latter would be used to assess the health message. Participants might therefore respond as conformist binge drinkers and deny the message in order to protect their binge drinker identity.

\section{Method}

Population. A total of 214 students (188 women), aged 17-25 years $\left(M_{\text {age }}=19.42\right.$ years, $\left.S D_{\text {age }}=1.39\right)$ from various French universities received an email invitation. They freely agreed to take part in this experiment without any monetary or credit compensation. They were randomly assigned to one of six experimental conditions in a 2 (no normative information vs. low descriptive binge-drinking norm) $\times 3$ (no self-affirmation vs. value affirmation vs. group affirmation) between-participants factorial design.

Procedure. First, participants completed the value-affirmation procedure. They listed ten values (i.e., freedom, ambition, tolerance, power, independence, equality, politeness, creativity, justice, autonomy) in order of importance, either according to their own preferences (self-affirmed) or those of their friends (group-affirmed). In the self-affirmed condition, they explained why the first value was important to them by giving an example from their everyday life. Contrary to the normal no self-affirmation condition, we chose to ask participants to explain why the value listed bottom was not important in their everyday lives, and to give an example (Sherman et al., 2000, Exp. 1). In most experiments using value 
affirmation, in the control condition (i.e., no self-affirmation) participants are informed that the value ranked last could be important for another student belonging to the same university (e.g., Sherman et al., 2000, Exp. 2). However, given our hypothesis about group membership, we preferred to avoid any mention of another person, as this might have made a group salient. In the group-affirmation condition, participants also ranked the values in order of importance, and justified their choices in terms of their friends' lives. Then all the participants read the article we had presented in Experiment 1 about the effects of binge drinking. As in Experiment 1 , they either learned that just $17 \%$ of young people had engaged in binge drinking at least once (i.e., information about a low descriptive norm) or else received no normative information at all. As in Experiment 1, they then rated items on message acceptance $(r=.35, p<.001)$ and alcohol consumption (Cronbach's $\alpha=.85)$, and reported whether they had already experienced binge drinking.

\section{Results}

Manipulation checks. We ran an ANOVA on alcohol intake to find out whether this variable was influenced by the experimental conditions. The ANOVA did not reveal main effects of either the self-affirmation variable, $F(2,208)=1.01, p=.37$, or the normative information variable, $F(1,208)=.15, p=.70$. Nor was there any interaction effect, $F(2,208)$ $=.59, p=.56$. Alcohol consumption was therefore treated as a predictor in subsequent analyses. Moreover, alcohol consumption was correlated with the self-reported item on binge drinking, $\rho=.41, p<.001$.

Message acceptance. We submitted the data to a linear regression with interaction effects. Self-affirmation was dummy coded into two variables: The first dummy variable (d1: $0=$ no self-affirmation, $1=$ self-affirmation and $0=$ group-affirmation) and the second dummy variable $(\mathrm{d} 2: 0=$ no self-affirmation, $0=$ self-affirmation and $1=$ group-affirmation $)$. The alcohol consumption and normative information variables $(-1=$ no normative information 
and $1=$ low drinking norm) were centered (see, Aiken \& West, 1991, for the method). We entered both covariates (age, sex) in the hierarchical regression in the first step, and analyzed two main effects (alcohol consumption and normative information) in the second step. The two dummy-coded variables of self-affirmation (d1 and d2) were entered in Step 3. Step 4 tested the two-way interaction terms between affirmation and normative information $(\mathrm{d} 1 \times$ normative and $\mathrm{d} 2 \times$ normative). The other two-way interactions between alcohol consumption and affirmation $(\mathrm{d} 1 \times$ consumption and $\mathrm{d} 2 \times$ consumption $)$ and between alcohol consumption and normative information were tested in Steps 5 and 6, respectively. Finally, the three-way interaction was entered in Step $7(\mathrm{~d} 1 \times$ Consumption $\times$ Normative feedback and $\mathrm{d} 2 \times$ Consumption $\times$ Normative feedback).

First of all, there was a significant effect of alcohol consumption on message acceptance. Overall, the more alcohol participants were used to drinking, the less they accepted the message's conclusions, $\beta=-.43, t(209)=-6.63, p<.001$ (Hypothesis 1 ). Being told the health risks of inappropriate behavior prompted participants to deny the message's conclusions. We observed a significant three-way interaction effect between alcohol consumption, social norm and self-affirmation, $\Delta R^{2}=.032, \Delta F(2,200)=4.57, p=.011$. To better understand this interaction, we calculated the slopes in each experimental condition.

No self-affirmation condition. Without self-affirmation, the experiment replicated the defensive bias in the face of a threatening message, as the more alcohol participants were accustomed to drinking, the more they denied the message's conclusion, regardless of the normative information (no normative information condition: $\beta=-.41, t(202)=-3.26, p=.001$ and low drinking norm condition: $\beta=-.52, t(202)=-3.87, p<.001)$. Moreover, there was no statistical difference between these two normative conditions (no interaction effect), $\beta=-.06$, $t(202)=-.61, p=.54$. In other words, without self-affirmation, participants used discrediting in similar ways in both the no normative information and low drinking-norm conditions. 
SELF-AFFIRMATION AND ALCOHOL

Self-affirmation condition. In the no normative information condition, the defensive bias was countered by self-affirmation, $\beta=-.06, t(202)=.31, p=.75$ (see Fig.2, bottom). In other words, self-affirmation uncoupled the relationship between alcohol consumption and message acceptance. In the low drinking (17\%) norm condition, however, the defensive bias persisted after value-affirmation, $\beta=-.28, t(202)=-2.56, p=.011$, and did not differ from discrediting in the no self-affirmation and low descriptive norm conditions, $\beta=-.16, t(202)=$ $-1.41, p=.161$ (see Fig.2, top).

Group affirmation condition. In the no normative information condition, group affirmation did not affect the defensive bias, such that the more alcohol participants were accustomed to drinking, the less they accepted the message's conclusions, $\beta=-.55, t(202)=-$ $3.60, p<.001$. Furthermore, the group affirmation condition did not differ from the no selfaffirmation condition, $\beta=.091, t(202)=.70, p=.48$. In the low $(17 \%)$ drinking norm condition, by contrast, group affirmation significantly increased the defensive bias, $\beta=-1.96$, $t(202)=-5.11, p<.001$, compared with no self-affirmation, $\beta=.93, t(202)=3.54, p<.001$, and value affirmation, $\beta=1.06, t(202)=4.22, p<.001$.

\section{Discussion}

Results tended to confirm the findings of the first experiment, by showing that selfaffirmation reduces the threat to self-integrity when people are not told about the drinking norm (Sherman et al., 2000). Again, we observed that self-affirmation does not necessarily replace the spontaneous coping strategy of discrediting. As hypothesized, normative information diminished the impact of self-affirmation. Results also confirmed our prediction that group affirmation (here, friends) would increase the defensive bias in the low descriptive norm condition. This means that people are probably focused on group concerns. Affirming a group value heightened the discrepancy between the participants' drinking consumption and the low norm, and thus prompted them to discredit the message more. Similarly, group 
affirmation in the no normative information condition probably primed group-related beliefs (here, overestimation of binge drinking). Young people need to be convinced that drinking is positively perceived by their peers. Consequently, discrediting serves to protect their grouprelated self.

The difference between the effects of value- and group-affirmation has several implications for our understanding of the self-affirmation process. Up to now, the explanation for these effects has been that when an important element of the self-concept (e.g., a value, acquaintances) is activated, it spreads to the other elements of the individual's social and personal identity. There is, however, one fundamental difference, in that friend affirmation probably activates the individual's social identity and the social norms associated with his or her group of friends. Given the association between the perceived drinking norm in the French student population and alcohol consumption by (see pilot study), the more participants drank, the greater the perceived discrepancy between their drinking behaviors and the low (17\%) drinking norm described in the experiment. Our comparison of group and self-affirmation suggests that these two procedures activate different self-elements. This is discussed at greater length in the General Discussion.

\section{Experiment 3}

The previous two experiments stressed that the relationship between drinking behaviors and general acceptance of the health message depended on self-affirmation and the salience of a low drinking norm. This third experiment was intended to address some of their shortcomings and provide a theoretical explanation. Above all, this third experiment sought to reproduce the three-way interaction effect observed in Experiments 1 and 2 on general health message acceptance (Hypothesis 3.1). It was important to rule out any suspicions about participants' habitual drinking behavior as an independent variable, so we measured it one week before the experiment. 
First, we argued that there are two threats to self-integrity when individuals read a health message and learn that the norm is low. Reasoning that drinking alcohol at parties is extremely normative, we assumed that the health message per se (i.e., no normative information) would reveal a mismatch between alcohol consumption and the perceived social norm (or subjective norm), thus creating a threat to self-integrity. If this was indeed the situation, then we would expect the subjective norm to predict acceptance, and habitual alcohol consumption to constitute a confounding variable. If a low drinking norm were made salient then, as we have argued, it would constitute another threat to self-integrity.

Participants would compare their behavior with the descriptive norm. In the absence of selfaffirmation, the subjective norm would predict message acceptance in the no normative information condition, whereas both subjective norm and alcohol consumption would predict general acceptance in the low drinking norm condition (Hypothesis 3.2). Another implication of the double threat assumption is that individuals would experience less self-integrity in the low drinking norm condition (two threats) than in the no normative information condition (one threat). We therefore administered a self-integrity scale (Hypothesis 3.3). Informing individuals about a low drinking norm makes the discrepancy between their behaviors and the social norm salient for drinkers. Given that one function of norms is to inform people how to behave and think, it implies that people are misinformed about the drinking norm. Norms belong to the self-concept, so this type of announcement makes people think that they have no clear knowledge about the prevailing social norm. One component of self-knowledge is selfclarity (Campbell et al., 1996). We therefore predicted that the announcement of a low drinking norm would create a lack of self-clarity, owing to the discrepancy with the ingroup social norm (Hypothesis 3.4).

Second, we assumed that the simultaneous presence of self-affirmation and the low drinking norm would generate a discrepancy in identity (Hypothesis 3.5). We assumed that 
self-affirmation and the announcement of a low drinking norm would each activate an identity element, respectively a value and a drinker identity. Thus, self-knowledge would be more accessible. Concretely, in line with Reed and Aspinwall (1998), in the no normative information condition, self-affirmed participants would respond quicker than those in the no self-affirmation condition to a questionnaire with self-focused items. Moreover, we assumed that the announcement of a low drinking norm would prompt participants to categorize themselves as drinkers. This announcement would therefore facilitate responses to the selfrelated questionnaire in the low drinking norm condition compared with the no normative information condition. Finally, if the self-affirmation procedure and the announcement of a low drinking norm did indeed trigger an identity discrepancy, then participants would find it harder to access their self-concept and would respond more slowly. In other words, the selfaffirmation (without the low drinking norm) and low drinking norm conditions would activate a single identity and thus facilitate access to self-knowledge. Conversely, when no identity was activated (no self-affirmation/no normative information condition) or when there was an identity discrepancy, self-knowledge would be less easy to access, and responses to selfrelated items would be correspondingly slower.

Third, we hypothesized that the announcement of a low descriptive norm threatens group cohesion (Hypothesis 3.6). Describing a low binge drinking norm might trigger a feeling of deviance among the heaviest drinkers, and threaten group cohesion (Abrams et al., 2002). These individuals might attempt to preserve this cohesion by overestimating the beneficial effects of binge drinking at parties with friends in terms of socialization, as opposed to relaxation (Lee, Maggs, Neighbors, \& Patrick, 2011; Park, 2004). We predicted that individuals in the low binge-drinking norm condition would emphasize the role of alcohol in socializing and creating bonds as a function of their alcohol-related habits. Socialization arguments such as these serve to justify unhealthy behaviors without creating a self-threat. 
Having good reasons to drink may protect people's positive self-integrity, in that they do not perceive heavy drinking to be a threat to group cohesion. In other words, external justifications protect the drinker's identity and underscore the utility of alcohol for group cohesion. Overjustifying binge drinking as a way of socializing allows individuals to continue conforming to the social norm (Cialdini \& Trost, 1998). We predicted that the more participants were accustomed to drinking, the more they would use the coping strategy of citing external justifications in the low binge-drinking norm condition. If participants read a message about the dangers of alcohol that did not contain any normative information, then self-affirmation would protect their positive self-integrity. That is, it would protect their identity and spare them from having to justify their alcohol-related behavior. In other words, participants would not need to resort to external justifications to maintain positive selfintegrity. They would be able to uncouple their self-concept and external justifications.

Finally, assuming that the low binge drinking norm condition would reduce self-clarity and force individuals to overestimate the role of alcohol in socialization, we predicted that selfclarity would mediate the relationship between alcohol intake and the socialization justification.

\section{Population and experimental design}

A total of 166 students (112 women, $M_{\text {age }}=21.11$ years, $S D=1.82$, range $=18-25$ years) from Aix-Marseille University, France, voluntarily took part in the third experiment. They were randomly assigned to one of four experimental conditions in a 2 (self-affirmed vs. no self-affirmation $) \times 2$ (no normative information vs. low descriptive norm information) factorial between-participants design.

\section{Method}

This third experiment consisted of two sessions one week apart. During the first session (baseline), participants were approached on campus by a female experimenter who 
invited them to take part in an alcohol-related study. If they agreed, participants began by filling out a 4-item scale on the subjective norm related to drinking (Cronbach's $\alpha=.84$ ) adapted from Johnston and White (2003)'s article. Participants were asked to imagine what most people who are important to them would think at a party held in the following two weeks. They responded on 7-point bipolar items (Disapprove/Approve, Undesirable/Desirable, Should not at all/Should, Do not encourage at all/Encourage very much). Second, they responded to the items on alcohol intake used in Experiments 1 and 2 (Cronbach's $\alpha=.70$ ). Each of these items was transformed into $z$ score, and an alcohol intake score was then computed from the three resulting $z$ scores. Participants then responded to a single item asking whether they had already experienced binge drinking.

Participants provided their email addresses and were contacted one week later. They clicked on an Internet link to participate in the second session on line. The procedure was identical to that of the second experiment. Participants underwent the value-affirmation procedure and read the article about the dangers of binge drinking. As before, the normative information was manipulated at the beginning of the article.

Dependent measures. In order to confirm our assumption about the accessibility of the self-concept, we designed a 36-item questionnaire about identity (group identification with friends, self-uncertainty, self-clarity, self-integrity, justifications for drinking and acceptance). This questionnaire took several minutes to complete, and required participants to ask questions about themselves. The timer was switched on when the participants started the experiments and switched off when they had filled out the last item. In other words, the duration of the experiment included the time taken to read the health message and respond to the items. For technical reasons, we were not able to subtract the reading time. However, Klein and Harris (2009)'s experiment showed that the reading time is exactly the same regardless of habitual drinking behaviors and self-affirmation. We could therefore attribute 
the difference in duration to the time needed to process the self-relevant questions (i.e., response time).

The other dependent variables were collected in the following order.

Self-integrity. This was measured with an 8-item scale (e.g., "I have the ability and skills to deal with whatever comes my way", "I feel that I'm basically a moral person", Cronbach's $\alpha=.75$ ) taken from Sherman and colleagues (2009). Participants responded by indicating the extent to which they agreed with each statement (from $1=$ Strongly disagree to $7=$ Strongly agree)

Self-clarity. Self-clarity was measured on an abridged version (5 items) of Campbell and colleagues' (1996) scale, developed by Smith and colleagues (2007). Items (e.g., "My beliefs about myself conflict with one another", Cronbach's $\alpha=.71$ ) were rated on a selfconcept clarity scale ranging from 1 (Very slightly or not at all) to 5 (Extremely).

External justifications for drinking. Inspired by themes taken from Park (2004), participants were asked to imagine the extent to which drinking alcohol at a party with friends might bring them benefits, rating two sets of items on scales ranging from 1 (Does not help at all) to 7 (Helps a lot). Some external justifications were related to socializing with friends or acquaintances ("Meeting a new boy- or girlfriend", "Making new acquaintances/friends", "Strengthening bonds between friends", "Bringing friends together"; Cronbach's $\alpha=.86$ ), while others were linked to relaxation ("Forgetting the problems of daily life", "Relieving stress", "Feeling relaxed"; Cronbach's $\alpha=.87)$. These two sets of items were correlated, $r(170)=.61, p<.001$

Acceptance of health message and perceived norm. The two health message acceptance items were the same as those used in the first two experiments (taken from Sherman et al., 2000), $r=.38, p<.001$. Finally, participants responded to an open-ended item to check the number of students they thought had already experienced binge drinking ("Please 
SELF-AFFIRMATION AND ALCOHOL

give your estimate in percentage terms of the number of students who have indulged in binge drinking").

\section{Results}

\section{Manipulation checks.}

Binge drinking. As observed in Experiments 1 and 2, the alcohol intake index was correlated with the binge drinking item, $\rho=.39, p<.001$.

Perceived norm. We ran an ANCOVA on the 2 (no self-affirmation vs. selfaffirmed) $\times 2$ (no normative information vs. $17 \%$ descriptive norm) between-participants factorial design to probe participants' perceptions of the descriptive norm, with alcohol intake, age and sex as covariates. Results revealed a main effect of normative information, $F(1,164)=29.14, p<.001, \eta^{2}=.15$. In the no normative information condition, participants estimated that on average, $59.07 \%(S D=20.53)$ of other students had already experienced binge drinking. By comparison, in the $17 \%$ condition, participants provided lower estimates $(M=41.07 \%, S D=24.35)$. There was no main effect of value-affirmation procedure, $F<1$. Finally, we found a significant interaction effect, $F(1,164)=7.17, p=.008, \eta_{P}^{2}=.04$, indicating that self-affirmation increased estimates of the binge drinking norm in the no normative information condition $\left(M_{\text {No self-affirmation }}=54.187, S D=21.28\right.$ and $M_{\text {self-affirmed }}=$ 63.75, $S D=18.85)$, whereas it decreases estimates of this norm in the low binge-drinking norm condition $\left(M_{\text {No self-affirmation }}=45.74, S D=22.93\right.$ and $\left.M_{\text {self-affirmed }}=37.13, S D=24.97\right)$.

\section{Dependent variables.}

For all subsequent analyses, we used multi-step multiple regressions with interaction effects (see Aiken \& West, 1991). As binge drinking is differently experienced in France, depending on the individual's age and sex, these two variables were entered in the multiple regressions as covariates. Moreover, as there was an effect of response time in the second session, this variable was also entered as a covariate. We tested the covariates ( $\operatorname{sex}[-1=$ 
women and $1=$ men], age) in Step 1. In Step 2, we analyzed the main effects of alcohol consumption (centered), self-affirmation $(-1=$ no self-affirmation and $1=$ self-affirmed) and normative information $(-1=$ no normative information and $1=$ low descriptive norm). The three two-way interaction terms (Self-affirmation $\times$ Normative information, Alcohol consumption $\times$ Self-affirmation, Alcohol consumption $\times$ Normative information) and the critical three-way interaction term (Alcohol consumption $\times$ Self-affirmation $\times$ Normative information) were tested in Steps 3 and 4, respectively.

Health message acceptance predicted by alcohol consumption. In our first two experiments, we measured reported alcohol intake right the experimental procedure. In this third experiment, however, alcohol intake was measured one week prior to the experimental procedure, in order to make sure that it was a predictor of health message acceptance, and not the other way round (i.e., effect of acceptance on reported alcohol consumption). Although this variable was measured last, not first, the purpose of the analysis was to find out whether or not this third experiment reproduced the results for health message acceptance obtained in the previous two experiments. That is to say, whether or not participants discredited the message when they were in the self-affirmed and low descriptive drinking norm conditions. First, health message acceptance depended on drinking habits, $\beta=-.34, t(56)=-4.43, p<$ .001. The more alcohol participants were accustomed to drinking, the less they accepted the health message's conclusions. When we looked at whether this experiment replicated the three-way interaction (Hypothesis 3.1) between alcohol intake, self-affirmation and normative information observed in the first two experiments, we found only borderline significance, $\beta=$ $-.15, t(152)=-1.91, p=.057$. In order to break this three-way interaction down, we ran regressions of alcohol intake on acceptance in the four experimental conditions. When participants were not self-affirmed, alcohol intake marginally predicted acceptance of the health message in the no normative information condition, $\beta=-.30, t(36)=-1.85, p=.072$, 
and significantly so in the low drinking norm condition, $\beta=-.46, t(49)=-3.25, p=.002$. As expected, when participants were self-affirmed, they responded differently, depending on the normative condition. When they were not given any normative information, there was no relationship between alcohol intake and acceptance, $\beta=-.03, t(32)=-.18, p=.859$. In other words, value affirmation reduced reliance on discrediting as a coping strategy. As observed previously, value-affirmation did not reduce discrediting in the low drinking norm condition, $\beta=-.57, t(48)=-4.74, p<.001$. Participants continued to discredit the health message according to their alcohol intake. In addition, there was a significant two-way interaction between normative information and alcohol intake, $\beta=-.20, t(157)=-2.71, p=.008$. None of the other main effects or interaction effects was significant (see left-hand side of Table 1).

We also tested our model by controlling for the subjective norm. We ran the same multiple regressions as before, except that subjective norm was entered as a covariate in Step 1 (for full results, see right-hand side of Table 1). This covariate significantly predicted acceptance, $\beta=-.39, t(158)=-5.37, p<.001$. The more participants believed in a bingedrinking norm, the more they discredited the health message. Interestingly, the three-way interaction ceased to be significant when subjective norm was entered as a covariate, $\beta=-.09$, $t(151)=-1.28, p=.203$ (Hypothesis 3.2), leaving a two-way interaction between alcohol consumption and normative information, $\beta=-.17, t(152)=-2.30, p=.023$. This means that when the subjective norm was controlled for, and whatever the self-affirmation condition, alcohol consumption predicted acceptance in the low descriptive norm condition, $\beta=-.45$, $t(88)=-3.69, p<.001$, but not in the no normative information condition, $\beta=-.07, t(69)=-$ $.54, p=.592$. In other words, as previously observed, alcohol consumption was not a predictor in the no normative information condition, regardless of whether participants were self-affirmed. Alcohol consumption marginally predicted acceptance, $\beta=-.30, t(36)=-1.85, p$ $=.072$, in the no normative information and no affirmation condition, but when it was entered 
together with subjective norm in a multiple regression, $\beta=-.07, t(69)=-.54, p=.592$, it behaved as a confounding variable (Hypothesis 3.2). Only subjective norm still marginally predicted acceptance, $\beta=-.34, t(35)=-1.88, p=.068$.

Health message acceptance predicted by subjective norm. We sought to examine the subjective norm's influence on health message acceptance further. We ran multi-step regressions as before (except that subjective norm replaced alcohol consumption). In Step 1, we entered the covariates (sex, age, response time and alcohol consumption). In the second step, we tested the main effects (subjective norm [centered], normative information and selfaffirmation). The two-way interaction terms were analyzed in the third step, and the three-way interaction in the fourth step. Overall, two significant effects emerged (for the other effects, see left-hand side of Table 2): a main effect of subjective norm, $\beta=-.21, t(155)=-2.63, p=$ .009 , was modulated by an interaction between subjective norm and self-affirmation, $\beta=-.15$, $t(152)=-2.04, p=.043$. This interaction effect means that the link (in absolute values) between subjective norm and acceptance was higher in the no self-affirmation condition, $\beta=-$ $.36, t(76)=-3.21, p=.002$, than in the self-affirmation condition, $\beta=-.24, t(81)=-1.23, p=$ .029. In other words, self-affirmation significantly decreased the effect of subjective norm on acceptance. The threat to self-integrity induced by the discrepancy with the subjective norm was partly uncoupled by self-affirmation.

Self-integrity. To check whether the announcement of a low drinking norm was more threatening to self-integrity than the condition without this information, we ran a hierarchical regression on the self-integrity score. We observed a significant effect of normative information, $\beta=-.18, t(76)=-2.27, p=.025$ (Hypothesis 3.3). Participants in the low descriptive norm condition reported lower self-integrity $(M=4.80, S D=.79)$ than in the no normative information condition $(M=5.08, S D=.79)$. Analysis also yielded a marginal effect of alcohol consumption on self-integrity, $\beta=-.18, t(158)=-1.83, p=.070$. The more 
alcohol they were accustomed to drinking, the more participants' self-integrity decreased.

There was no other main effect or interaction effect.

Self-clarity. Analysis showed that alcohol intake predicted self-concept clarity, $\beta=-$ $.16, t(166)=-2.06, p=.041$. However, this result was modulated by a significant interaction effect between alcohol intake and normative information, $\beta=-.16, t(161)=-2.03, p=.044$, indicating that without normative information, self-clarity was not predicted by alcohol intake, $\beta=-.03, t(74)=-.24, p=.808$, whereas in the low descriptive norm condition it was, $\beta$ $=-.32, t(92)=-3.31, p=.001$ (Hypothesis 3.4). The more alcohol participants drank, the more they felt their self-concept lacked clarity. In other words, the heaviest drinkers had less knowledge about their self-concept than the other drinkers. This results supports Hypothesis 3.3. None of the other main and interaction effects were significant.

Response times. We sought to find out whether alcohol consumption was linked to the time it took to respond to the self-related questionnaire, as a function of the selfaffirmation and normative information variables. Again, we tested these effects with a hierarchical regression featuring the interaction terms. Sex, age and subjective norm were entered as covariates in Step 1. First, analysis yielded a significant effect of alcohol intake on response times, $\beta=.23, t(159)=2.73, p=.007$. Self-affirmation and normative information had no effect on response times. Analysis also yielded a marginally significant interaction effect between the self-affirmation and normative information variables, $\beta=.15, t(156)=$ $1.94, p=.054$. This effect indicated that the difference in response times tended to decrease between the no normative information $(M=17.26, S D=8.65)$ and low descriptive norm conditions $(M=15.93, S D=7.28)$ when the participants were not self-affirmed, and increase when the participants were self-affirmed $\left(M_{\text {No normative information }}=15.74, S D=6.25\right.$ and $M_{\text {Low }}$ drinking norm $=19.19, S D=11.09)$. Hypothesis 3.5 was supported by a significant three-way interaction effect, $\beta=.22, t(155)=2.74, p=.007$. To break this effect down, we ran 
regressions in each experimental condition between alcohol consumption and response times.

Alcohol consumption predicted response times in the no self-affirmation/no normative information and self-affirmation/low drinking norm conditions, $\beta=.48, t(33)=2.45, p=.020$

and $\beta=.38, t(46)=2.35, p=.023$, respectively. In these conditions, the more alcohol

participants were accustomed to drinking, the more time they needed to respond to the self-

related questionnaire. By contrast, in the other two conditions, there was no significant

relationship between alcohol consumption and response times.

External justifications for drinking. In order to ascertain whether the

announcement of a low drinking norm generated fear of group cohesion disintegrating, we looked at whether participants sought to justify the usefulness of drinking alcohol in terms of forging relationships with friends (Hypothesis 3.6).

Socialization. First, the more participants drank at parties, the more they cited socialization arguments to justify their drinking, $\beta=.26, t(168)=3.44, p<.001$. Drinking behavior was justified by an enhanced ability to forge social relationships. This effect was modulated by an interaction effect between alcohol consumption and social norm, in support of our hypothesis, $\beta=.15, t(160)=1.98, p=.05$. In other words, only in the low (17\%) drinking norm condition did alcohol intake predict social motivation, $\beta=35, t(92)=3.57, p=$ .001 , as there was no relationship between alcohol consumption and social relationships in the no normative information condition, $\beta=.15, t(74)=1.26, p=.212$. There was no other main effect or interaction effect, all $t \mathrm{~s}<1$.

Relaxation. In order to demonstrate that the low descriptive norm condition only influenced socialization-related justifications, we ran multiple regressions with interaction effects on the relaxation justification for drinking. We only found a main effect of alcohol intake on relaxation, $\beta=.25, t(159)=3.19, p=.002$. The more alcohol participants drank, the 
more they thought that drinking alcohol enabled them to relax with friends at parties. There was no other main or interaction effect.

The behavior-socialization link mediated by self-concept clarity. We also sought to ascertain whether self-concept clarity was a mediator between alcohol intake and socialization as an external justification in the $17 \%$ condition (see Fig. 3). The socialization justification for drinking alcohol was predicted both by alcohol intake (direct effect), $\beta=.40, t(91)=4.23, p<$ .001 , and by self-clarity (mediator), $\beta=-.35, t(91)=-3.57, p=.001$. Moreover, alcohol intake predicted self-concept clarity, $\beta=-.28, t(91)=-2.74, p=.007$. Finally, we analyzed the indirect effect between alcohol intake and the socialization justification by entering selfconcept clarity in the multiple regressions, $\beta=.33, t(91)=3.46, p=.001$. We tested whether the indirect effect was statistically different from the direct effect. Tests revealed a difference between the two, Sobel's $z=1.93, p=.053 ; 95 \%$ CI [0.0258, 0.4886], with 5000 resamples. In other words, the relationship between alcohol intake and the socialization justification was partially mediated by self-concept clarity in the $17 \%$ condition, regardless of self-affirmation.

\section{Discussion}

This third experiment yet again confirmed our prediction that a self-affirmation procedure would not reduce discrediting among participants in the low binge drinking norm condition according to their alcohol consumption. Importantly, it replicated the findings of the first two experiments, even though alcohol-related behavior was measured prior to the experimental procedure. It appeared to show that health message discrediting is preferred to self-affirmation as a self-protection strategy.

The threat to self-integrity was differently experienced according to whether or not the health message included the low descriptive norm. First, the announcement of a low drinking norm decreased self-integrity compared with the no normative information condition. This result seems to indicate that the low drinking norm announcement was indeed 
a threat to self-integrity. Second, the subjective norm was a predictor of acceptance in both the no normative information and low descriptive norm conditions. Moreover, in the low descriptive norm condition, alcohol consumption also predicted health message acceptance. In other words, in the low descriptive norm condition, people had to manage a double self-threat, whereas in the no normative condition, they were only exposed to a single self-threat. Selfaffirmation obviated the need to resort to discrediting in the no normative information condition (i.e., no link between drinking behavior and acceptance). Neither subjective norm nor alcohol consumption predicted acceptance. Self-affirmation did, however, have a specific effect on acceptance in the low descriptive norm condition. The threat to self-integrity induced by the discrepancy with the subjective norm was reduced by the self-affirmation procedure. However alcohol consumption continued to predict discrediting. This third experiment suggests that participants preferred to manage each threat by adopting their own specific and appropriate coping strategy as a function of experimental condition. Proposing a self-affirmation strategy prior to the self-threat did not necessarily mean it would be used.

We put forward two major explanations for the lack of effectiveness in disrupting the link between drinking behavior and acceptance when people are confronted with a low drinking norm. First, to preserve their self-integrity, people need to be to retrieve selfresources. This experiment suggests that some circumstances hamper retrieval from memory. Participants needed more time to respond to a self-related questionnaire. Second, the announcement of a low descriptive norm is a deviance situation for drinkers, especially very heavy drinkers. Results showed that participants lost self-clarity and cited the forging of social bonds to justify their drinking behavior. This confirms the impossibility of using selfaffirmation to preserve one's self-integrity when the threat depends partly on others (PrewittFreilino \& Bosson, 2008). Deviance had several consequences for self-integrity. We found that the low descriptive norm condition was associated with lower self-integrity than the no 
normative information condition was. However, the announcement of the low drinking norm highlighted a risk of rejection and jeopardized group cohesion. Self-affirmation seemed unable to manage this threat. Self-affirmed participants therefore continued to justify their behavior by citing the usefulness of alcohol for creating relationships. Despite being a threat to self-integrity, the feeling of deviance triggered the use of coping strategies (here, socialization justifications and discrediting) rather than the use of self-affirmation.

\section{General Discussion}

Informing people about the health risks of alcohol consumption and providing a low binge-drinking descriptive norm affects the choice of coping strategy. Individuals prefer to discredit the message's conclusion rather than to resort to a self-affirmation strategy. We observed a robust effect in the low binge-drinking norm condition across all three experiments, as none of the self-affirmation procedures we used (i.e., attribute affirmation, value affirmation and group affirmation) uncoupled the relationship between drinking habits and acceptance of the message's conclusions. Results suggest that the efficiency of selfaffirmation is undermined by the discrepancy between the descriptive norm and alcoholrelated behaviors. The present study therefore highlights some of the limitations of using a combination of social norms and self-affirmation procedures to encourage target audiences to accept health messages that run counter to their past behavior.

\section{Theoretical Implications for Self-Affirmation Theory}

This observation can help us gain a clearer grasp of the self-affirmation process.

Self-cognition network. Many studies have highlighted the psychological benefits of selfaffirmation in a multitude of situations (e.g., cognitive dissonance, stereotype threat, threatening information). However, self-affirmation cannot be used to protect the self-concept in every threatening situation. There are a number of limitations to protecting one's positive self-integrity with a self-affirmation procedure (Blanton et al., 1997; Prewitt-Freilino \& 
Bosson, 2008; Shapiro et al., 2013; Sherman et al., 2009). Our research suggests that selfaffirmation is a potent self-protection strategy, providing the threatening information does not reduce self-clarity. This has major implications for self-affirmation theory. As previously suggested by Sherman and Hartson (2011), an affirmed value or attribute activates a selfrelated cognition network. In other words, activation spreads from a single important element of identity to other cognitions. For this reason, the relationship between all the different activated cognitions must be free of uncertainty and identity conflict. If cognitive relations are damaged, this can hinder the spread of activation.

Schematically, identity comes in two parts: personal identity and social identity. By activating one or other of these parts, Experiment 2 brought to light a difference in the affirmation of the collective versus the personal self. This suggests that the activation of personal identity does not recruit the same self-cognition network as that of social identity. In other words, affirming an important self-element does not activate overall identity. This conclusion is also supported by the difference in the effects of attribute and value affirmation observed in Experiments 1, 2 and 3. The network activated in the wake of attribute or value affirmation (self-cognition) appeared to have varying amounts of self-resources. When the affirmation of creativity (attribute affirmation; Exp. 1) was effective (i.e., no normative information), it lessened- but did not totally uncouple-the relationship between previous alcohol-related behaviors and message acceptance, whereas value affirmation totally uncoupled it.

The activation of different self-cognition networks according to which identity element is activated may have several consequences. For instance, the norms that are activated may differ according to the mode of affirmation. Although several studies support the notion that group affirmation enables us to cope with self-threats, in Experiment 2, this procedure failed to uncouple the negative relationship between past alcohol-related behaviors 
and message acceptance. This can be attributed to the activation of a norm of binge or heavy drinking among the students and their friends. The group therefore prescribed behaviors that contradicted the health message. In other words, the threatening information (avoid binge drinking for health reasons) was set against the prescription of heavy drinking by the activated self-cognition network. By the same token, self-affirmed individuals presumably activate their own personal norms, including the desire for good health (Sherman \& Cohen, 2006). In other words, the self-affirmation procedure is a way of preserving one's personal norms without perceiving the information as threatening.

Perceiving the threatening information from a broader perspective. Affirming an important self-element enables individuals to change their perception of the threatening information (Critcher \& Dunning, 2015; Sherman \& Hartson, 2011; Sherman, 2013). Wakslak and Trope (2009) demonstrated that people perceive a higher level of construal after being selfaffirmed (see also Sherman et al., 2013). In particular, the self-concept is perceived of as being more coherent. As in our third experiment, Wakslak and Trope (2009, study 1) measured selfconcept clarity. The beneficial effects of self-affirmation may be felt if the incongruent norm does not undermine the perception of a coherent self-concept owing to deviance. If people feel unstable and incoherent, they may not find the necessary self- resources in their network of self-cognitions. Moreover, in our own study, even after participants had been self-affirmed, the information still seemed to be related to the self- concept when the incongruent norm was given salience. In other words, the higher level of construal generated by the self-affirmation process may subsequently be altered. In Wakslak and Trope (2009)'s study, the beneficial effects of self-affirmation were measured in the absence of any self-threat. These positive outcomes may sometimes be unsustainable, depending on the type of self-threat. The selfaffirmation procedure is a source of information about oneself. However, if another piece of information (e.g., normative) is also present 
during the processing, people may consider both pieces of information, thus inhibiting the beneficial effects of self-affirmation.

Self-regulation resources. Self-affirmation contributes to self-regulation, that is, "the capacity of organisms (here, human beings) to override and alter their responses" (Baumeister \& Vohs, 2007, p. 2). Individuals spontaneously use discrediting as a coping strategy when confronted with a health-risk message. However, self-affirmation enables individuals to access norms. In the situation of a health message without any normative information, the norm is probably a desire to be healthy. Thus, self-affirmation enables individuals to respond in a way that is coherent with this norm. Conversely, information about a low binge drinking norm may give salience to two conflicting norms: being healthy and socializing with friends. This conflict arises because the first norm encourages abstinence, whereas young people think they need to drink in order to achieve the second one. According to Baumeister and Vohs (2007), conflicting norms have an impact on the self-regulation process. Their interpretation was corroborated by our measure of self-clarity. The normative information (17\% of peers have engaged in binge drinking) affected the self-concept because participants felt more uncertain, incoherent and in conflict. In other words, the power of selfaffirmation to neutralize self-threats may be undermined if the self-regulation process is hindered. Then again, a recent study showed that self-affirmation can actually increase selfregulatory resources (Huynh, Stefanucci, \& Aspinwall, 2014). This suggests that the conditions for mobilizing self-resources in our study were altered or blocked by the low binge drinking norm, as self-affirmation slowed the retrieval of self-knowledge in the low drinking norm condition.

Self-affirmation and deviance. Self-affirmation is an undeniably potent process for preserving self-integrity (Sherman, 2013). In Experiment 3, however, a threat to self-integrity associated with a risk of deviance was managed in a way other than self-affirmation. This 
suggests that people weigh up the validity of a defensive strategy before using it. The use of self-affirmation does not dispel the risks of rejection and reduced group cohesion. Selfaffirmation alone cannot manage the overall threat. Trying to manage the threat by selfaffirmation could trigger other concerns. If people accepted the health message, for instance, they would have to take the normative information into account, and this would highlight the feeling of deviance.

\section{Conclusion}

Taken together, the results of our three experiments confirmed that self-affirmation reduces the defensive bias in the absence of normative information (Sherman \& Cohen, 2006; Sherman et al., 2000). Despite the self-affirmation procedure, however, the defensive bias persisted in the low binge-drinking norm condition. This observation could explain why low social norms have no influence on discrediting when they contradict excessively high perceived norms (Blanton et al., 2008).

These results suggest that self-affirmation cannot resolve both deviance and the threat to self-integrity. However, the absence of an effect of self-affirmation on acceptance does not mean that self-affirmation plays no role whatsoever. Self-affirmation may be oriented toward the defense of group concerns which, in turn, may sustain or strengthen health message discrediting.

People seek to protect their positive self-integrity any way they can. In the short term, they do not care about whether they shield themselves using discrediting or a selfaffirmation strategy. Only the end result (protecting the self-concept) is psychologically important, and the actual means to that end does not matter. Over the longer term, selfaffirmation seems to be more advantageous than discrediting. Future research will have to circumscribe the self-affirmation process more accurately, and look for ways of enhancing its beneficial effects in situations that are less favorable to self-affirmation. Notably, in the 
present study, we only measured overall acceptance. Future studies will need to explore whether our results can be generalized to personal acceptance (Harris \& Epton, 2009). 
SELF-AFFIRMATION AND ALCOHOL

\section{References}

Abrams, D., Marques, J., Bown, N., \& Dougill, M. (2002). Anti-norm and pro-norm deviance in the bank and on the campus: Two experiments on subjective group dynamics. Group Processes \& Intergroup Relations, 5(2), 163-182. doi:10.1177/1368430202005002922

Aiken, L. S., \& West, S. G. (1991). Multiple regression: Testing and interpreting interactions. Newbury Park, CA: Sage Publications.

Armitage, C. J., Harris, P. R., \& Arden, M. A. (2011). Evidence that self-affirmation reduces alcohol consumption: Randomized exploratory trial with a new, brief means of selfaffirming. Health Psychology, 30(5), 633-641. doi:10.1037/a0023738

Armitage, C. J., Harris, P. R., Hepton, G., \& Napper, L. (2008). Self-affirmation increases acceptance of health-risk information among UK adult smokers with low socioeconomic status. Psychology of Addictive Behaviors, 22(1), 88-95. doi:10.1037/0893164X.22.1.88

Aronson, J., Blanton, H., \& Cooper, J. (1995). From dissonance to disidentification: Selectivity in the self-affirmation process. Journal of Personality and Social Psychology, 68(6), 986-996. doi:10.1037//0022-3514.68.6.986

Aronson, J., Cohen, G. L., \& Nail, P. R. (1999). Self-affirmation theory: An update and appraisal. In E. Harmon-Jones \& J. Mills (Eds.), Cognitive dissonance: Progress on a pivotal theory in social psychology (pp. 127-147). Washinghton, DC: American Psychological Association.

URL: http://mc.manuscriptcentral.com/psai Email: reviews@psypress.co.uk 
Baumeister, R. F., \& Vohs, K. D. (2007). Self-regulation, ego depletion, and motivation. Social and Personality Psychology Compass, 1(1), 115-128. doi:10.1111/j.17519004.2007.00001.x

Blanton, H., Cooper, J., Slkurnik, I., \& Aronson, J. (1997). When bad things happen to good feedback: Exacerbating the need for self-justification with self-affirmations. Personality and Social Psychology Bulletin, 23(7), 684-692. doi:10.1177/0146167297237002

Blanton, H., Köblitz, A., \& McCaul, K. D. (2008). Misperceptions about norm misperceptions : Descriptive, injunctive, and affective "social norming" efforts to change health behaviors. Social and Personality Psychology Compass, 3, 1379-1399. doi:10.1111/j.1751-9004.2008.00107.x

Borsari, B., \& Carey, K. B. (2008). Descriptive and injunctive norms in college drinking: A meta-analytic integration. Journal of Studies on Alcohol, 64(3), 331-341.

Brewer, M. B., \& Gardner, W. (1996). Who is this "We"? Levels of collective identity and self representations. Journal of Personality and Social Psychology, 71(1), 83-93. doi:10.1037//0022-3514.71.1.83

Campbell, J. D., Trapnell, P. D., Heine, S. J., Katz, I. M., Lavallee, L. F., \& Lehman, D. R. (1996). Self-concept clarity: Measurement, personality correlates, and cultural boundaries. Journal of Personality and Social Psychology, 70(1), 141-156. doi:10.1037//0022-3514.70.1.141

Christensen, P. N., Rothgerber, H., Wood, W., \& Matz, D. C. (2004). Social norms and identity relevance: A motivational approach to normative behavior. Personality and Social Psychology Bulletin, 30(10), 1295-309. doi:10.1177/0146167204264480

URL: http://mc.manuscriptcentral.com/psai Email: reviews@psypress.co.uk 
SELF-AFFIRMATION AND ALCOHOL

Cialdini, R. B. (2003). Crafting normative messages to protect the environment. Current Directions in Psychological Science, 12, 105-109. doi:10.1111/1467-8721.01242

Cialdini, R. B. (2007). Descriptive social norms as underappreciated sources of social control. Psychometrika, 72(2), 263-268. doi:10.1007/s11336-006-1560-6

Cialdini, R. B., Demaine, L. J., Sagarin, B. J., Barrett, D. W., Rhoads, K., \& Winter, P. L. (2006). Managing social norms for persuasive impact. Social Influence, 1(1), 3-15. doi:10.1080/15534510500181459

Cialdini, R. B., Reno, R. R., \& Kallgren, C. A. (1990). A focus theory of normative conduct: Recycling the concept of norms to reduce littering in public places. Journal of Personality and Social Psychology, 58(6), 1015-1026. doi:10.1037/00223514.58.6.1015

Cialdini, R. B., \& Trost, M. R. (1998). Social influence: Social norms, conformity and compliance. In D. T. Gilbert, S. T. Fiske, \& G. Lindzay (Eds.), The handbook of social psychology (4th ed., pp. 1551-1192). New York: McGraw-Hill.

Cohen, G. L., \& Sherman, D. K. (2014). The psychology of change: Self-affirmation and social psychological intervention. Annual Review of Psychology, 65, 333-71. doi:10.1146/annurev-psych-010213-115137

Corbin, W. R., Iwamoto, D. K., \& Fromme, K. (2011). Broad social motives, alcohol use, and related problems: Mechanisms of risk from high school through college. Addictive Behaviors, 36(3), 222-30. doi:10.1016/j.addbeh.2010.11.004

URL: http://mc.manuscriptcentral.com/psai Email: reviews@psypress.co.uk 
Correll, J., Spencer, S. J., \& Zanna, M. P. (2004). An affirmed self and an open mind: Selfaffirmation and sensitivity to argument strength. Journal of Experimental Social Psychology, 40(3), 350-356. doi:10.1016/j.jesp.2003.07.001

Creswell, J. D., Lam, S., Stanton, A. L., Taylor, S. E., Bower, J. E., \& Sherman, D. K. (2007). Does self-affirmation, cognitive processing, or discovery of meaning explain cancerrelated health benefits of expressive writing? Personality \& Social Psychology Bulletin, 33(2), 238-250. doi:10.1177/0146167206294412

Critcher, C. R., \& Dunning, D. (2015). Self-affirmations provide a broader perspective on self-threat. Personality and Social Psychology Bulletin, 41(1), 3-18. doi:10.1177/0146167214554956

Dieterich, S. E., Stanley, L. R., Swaim, R. C., \& Beauvais, F. (2013). Outcome expectancies, descriptive norms, and alcohol use: American Indian and white adolescents. The Journal of Primary Prevention, 34(4), 209-219. doi:10.1007/s10935-013-0311-6

Epton, T., \& Harris, P. R. (2008). Self-affirmation promotes health behavior change. Health Psychology, 27(6), 746-752. doi:10.1037/0278-6133.27.6.746

Ferrer, R. A., Shmueli, D., Bergman, H. E., Harris, P. R., \& Klein, W. M. P. (2011). Effects of self-affirmation on implementation intentions and the moderating role of affect. Social Psychological and Personality Science, 3(3), 300-307. doi:10.1177/1948550611419265

Glasford, D. E., Dovidio, J. F., \& Pratto, F. (2009). I continue to feel so good about us: Ingroup identification and the use of social identity-enhancing strategies to reduce intragroup dissonance. Personality and Social Psychology Bulletin, 35(4), 415-27. doi:10.1177/0146167208329216

URL: http://mc.manuscriptcentral.com/psai Email: reviews@psypress.co.uk 
Griffin, D. W., \& Harris, P. R. (2011). Calibrating the response to health warnings: Limiting both overreaction and underreaction with self-affirmation. Psychological Science, 22(5), 572-8. doi:10.1177/0956797611405678

Gunn, G. R., \& Wilson, A. E. (2011). Acknowledging the skeletons in our closet: The effect of group affirmation on collective guilt, collective shame, and reparatory attitudes. Personality \& Social Psychology Bulletin, 37(11), 1474-1487. doi: $10.1177 / 0146167211413607$

Harris, P. R. (2011). Self-affirmation and the self-regulation of health behavior change. Self and Identity, 10(3), 304-314. doi:10.1080/15298868.2010.517963

Harris, P. R., \& Epton, T. (2009). The impact of self-affirmation on health cognition, health behaviour and other health-related responses: A narrative review. Social and Personality Psychology Compass, 3(6), 962-978. doi:10.1111/j.1751-9004.2009.00233.x

Harris, P. R., \& Napper, L. (2005). Self-affirmation and the biased processing of threatening health-risk information. Personality \& Social Psychology Bulletin, 31(9), 1250-1263. doi:10.1177/0146167205274694

Hogg, M. A., \& Reid, S. A. (2006). Social identity, self-categorization, and the communication of group norms. Communication Theory, 16(1), 7-30. doi:10.1111/j.1468-2885.2006.00003.x

Huynh, S., Stefanucci, J. K., \& Aspinwall, L. G. (2014). Self-affirmation counters the effects of self-regulatory resource depletion on height perception. Journal of Experimental Social Psychology, 52, 96-100. doi:10.1016/j.jesp.2014.01.003

URL: http://mc.manuscriptcentral.com/psai Email: reviews@psypress.co.uk 
Jessop, D. C., Simmonds, L. V, \& Sparks, P. (2009). Motivational and behavioural consequences of self-affirmation interventions: A study of sunscreen use among women. Psychology \& Health, 24(5), 529-44. doi:10.1080/08870440801930320

Johnston, K. L., \& White, K. M. (2003). Binge-drinking: A test of the role of group norms in the theory of planned behaviour. Psychology \& Health, 18(1), 63-77. doi:10.1080/0887044021000037835

Kallgren, C. A., Reno, R. R., \& Cialdini, R. B. (2000). A focus theory of normative conduct: When norms do and do not affect behavior. Personality and Social Psychology Bulletin, 26(8), 1002-1012. doi:10.1177/01461672002610009

Klein, W. M. P., \& Harris, P. R. (2009). Self-affirmation enhances attentional bias toward threatening components of a persuasive message. Psychological Science, 20(12), 14637. doi:10.1111/j.1467-9280.2009.02467.x

Klein, W. M. P., Harris, P. R., Ferrer, R. A., \& Zajac, L. E. (2011). Feelings of vulnerability in response to threatening messages: Effects of self-affirmation. Journal of Experimental Social Psychology, 47(6), 1237-1242. doi:10.1016/j.jesp.2011.05.005

Klein, W. M. P., Lipkus, I. M., Scholl, S. M., McQueen, A., Cerully, J. L., \& Harris, P. R. (2010). Self-affirmation moderates effects of unrealistic optimism and pessimism on reactions to tailored risk feedback. Psychology \& Health, 25(10), 1195-1208. doi:10.1080/08870440903261970

Kunda, Z. (1987). Motivated inference: Self-serving generation and evaluation of causal theories. Journal of Personality and Social Psychology, 53(4), 636-647. doi:10.1037//0022-3514.53.4.636

URL: http://mc.manuscriptcentral.com/psai Email: reviews@psypress.co.uk 
Lee, C. M., Maggs, J. L., Neighbors, C., \& Patrick, M. E. (2011). Positive and negative alcohol-related consequences: Associations with past drinking. Journal of Adolescence, 34(1), 87-94. doi:10.1016/j.adolescence.2010.01.009

Lewis, M. A., \& Neighbors, C. (2006). Descriptive drinking norms education : A review of the research on personalized normative feedback. Journal of American College Health, 54(4), 213-218. doi:10.3200/JACH.54.4.213-218

Liberman, A., \& Chaiken, S. (1992). Defensive processing of personally relevant health messages. Personality \& Social Psychology Bulletin, 18(6), 669-679. doi:10.1037/00223514.53 .4 .636

MacKinnon, D. P., Krull, J. L., \& Lockwood, C. M. (2000). Equivalence of the mediation, confounding and suppression effect. Prevention Science, 1(4), 1-13.

Major, B., \& O’Brien, L. T. (2005). The social psychology of stigma. Annual Review of Psychology, 56, 393-421. doi:10.1146/annurev.psych.56.091103.070137

Marques, J. M., \& Yzerbyt, V. Y. (1988). The black sheep effect: Judmental extremity towards ingroup members in inter- intra-group situations. European Journal of Social Psychology, 18(3), 287-292. doi:10.1002/ejsp.2420180308

McCrea, S. M., \& Hirt, E. R. (2011). Limitations on the substitutability of self-protective processes. Social Psychology, 42(1), 9-18. doi:10.1027/1864-9335/a000038

McQueen, A., \& Klein, W. (2006). Experimental manipulations of self-affirmation: A systematic review. Self and Identity, 5(4), 289-354. doi:10.1080/15298860600805325

URL: http://mc.manuscriptcentral.com/psai Email: reviews@psypress.co.uk 
Moreira, M. T., Smith, L. A., \& Foxcroft, D. (2010). Social norms interventions to reduce alcohol misuse in university or college students. The Cochrane Database Systematic Reviews, 8(3). doi:10.1002/14651858.CD006748.pub2

Neighbors, C., Lee, C. M., Lewis, M. A., Fossos, N., \& Larimer, M. E. (2007). Are social norms the best predictor of outcomes among heavy-drinking college students? Journal of Studies on Alcohol and Drugs, 68(4), 556-565.

Page, R. M., Ihasz, F., Hantiu, I., Simonek, J., \& Klarova, R. (2008). Social normative perceptions of alcohol use and episodic heavy drinking among Central and Eastern European adolescents. Substance Use \& Misuse, 43(3-4), 361-73. doi:10.1080/10826080701202866

Park, C. L. (2004). Positive and negative consequences of alcohol consumption in college students. Addictive Behaviors, 29(2), 311-321. doi:10.1016/j.addbeh.2003.08.006

Perkins, H. W., Linkenbach, J. W., Lewis, M. A., \& Neighbors, C. (2010). Effectiveness of social norms media marketing in reducing drinking and driving: A statewide campaign. Addictive Behaviors, 35(10), 866-874. doi:10.1016/j.addbeh.2010.05.004

Piane, G., \& Safer, A. (2008). Drinking behaviors, expectancies and perceived social norms among diverse college women. Journal of Alcohol \& Drug Education, 52(1), 67-79.

Prewitt-Freilino, J. L., \& Bosson, J. K. (2008). Defending the self against identity misclassification. Self and Identity, 7(2), 168-183. doi:10.1080/17405620701330706

Reed, M. B., \& Aspinwall, L. G. (1998). Self-affirmation reduces biased processing of healthrisk information. Motivation and Emotion, 22(2), 99-133.

doi:10.1023/A:1021463221281

URL: http://mc.manuscriptcentral.com/psai Email: reviews@psypress.co.uk 
Reno, R. R., Cialdini, R. B., \& Kallgren, C. A. (1993). The transsituational influence of social norms. Journal of Personality and Social Psychology, 64(1), 104-112. doi:10.1037/0022-3514.64.1.104

Richard, J.-B., Spilka, S., \& Beck, F. (2013). Les consommations de boissons alcoolisées parmi les 15-30 ans. Paris.

Rimal, R. N., \& Real, K. (2005). How behaviors are influenced by perceived norms: A test of the theory of normative social behavior. Communication Research, 32(3), 389-414. doi:10.1177/0093650205275385

Schultz, W. P., Nolan, J. M., Cialdini, R. B., Goldstein, N. J., \& Griskevicius, V. (2007). The constructive, destructive, and reconstructive power of social norms. Psychological Science, 18(5), 429-34. doi:10.1111/j.1467-9280.2007.01917.x

Scott, J. L., Brown, A. C., Phair, J. K., Westland, J. N., \& Schüz, B. (2013). Self-affirmation, intentions and alcohol consumption in students: A randomized exploratory trial. Alcohol and Alcoholism, 48(4), 458-63. doi:10.1093/alcalc/agt027

Shapiro, J. R., Williams, A. M., \& Hambarchyan, M. (2013). Are all interventions created equal? A multi-threat approach to tailoring stereotype threat interventions. Journal of Personality and Social Psychology, 104(2), 277-288. doi:10.1037/a0030461

Sherman, D. K. (2013). Self-affirmation: Understanding the effects. Social and Personality Psychology Compass, 7(11), 834-845.

Sherman, D. K., \& Cohen, G. L. (2002). Accepting threatening information: Self-affirmation and the reduction of defensive biases. Current Directions in Psychological Science, 
1(4), 119-123. 
Sherman, D. K., \& Cohen, G. L. (2006). The psychology of self-defense: Self-affirmation theory. In M. P. Zanna (Ed.), Advances in experimental social psychology (Vol. 38, pp. 183-242). San Diego, CA: Academic Press. doi:10.1016/S0065-2601(06)38004-5

Sherman, D. K., Cohen, G. L., Nelson, L. D., Nussbaum, D. A., Bunyan, D. P., \& Garcia, J. (2009). Affirmed yet unaware: Exploring the role of awareness in the process of selfaffirmation. Journal of Personality and Social Psychology, 97(5), 745-764. doi:10.1037/a0015451

Sherman, D. K., \& Hartson, K. A. (2011). Reconciling self-protection with self-improvement: Self-affirmation theory. In M. D. Alicke \& C. Sedikides (Eds.), The handbook of selfenhancement and self-protection (pp. 128-151). New York: Guilford Press.

Sherman, D. K., Kinias, Z., Major, B., Kim, H. S., \& Prenovost, M. (2007). The group as a resource: Reducing biased attributions for group success and failure via group affirmation. Personality \& Social Psychology Bulletin, 33(8), 1100-1112. doi: $10.1177 / 0146167207303027$

Sherman, D. K., Nelson, L. D., \& Steele, C. M. (2000). Do messages about health risks threaten the self? Increasing the acceptance of threatening health messages via selfaffirmation. Personality and Social Psychology Bulletin, 26(9), 1046-1058. doi:10.1177/01461672002611003

Sivanathan, N., Molden, D. C., Galinsky, A. D., \& Ku, G. (2008). The promise and peril of self-affirmation in de-escalation of commitment. Organizational Behavior and Human Decision Processes, 107(1), 1-14. doi:10.1016/j.obhdp.2007.12.004

URL: http://mc.manuscriptcentral.com/psai Email: reviews@psypress.co.uk 
Smith, J. R., Hogg, M. A., Martin, R., \& Terry, D. J. (2007). Uncertainty and the influence of group norms in the attitude-behaviour relationship. The British Journal of Social Psychology, 46(4), 769-92. doi:10.1348/014466606X164439

Spencer, S. J., Fein, S., \& Lomore, C. D. (2001). Maintaining one's self-image vis- à-vis others: The role of self-affirmation in the social evaluation of the self. Motivation and Emotion, 25(1), 41-65.

Spilka, S., Le Nézet, O., \& Tovar, M.-L. (2012). Les drogues à 17 ans : Premiers résultats de l'enquête ESCAPAD 2011. Tendances, 79(2).

Steele, C. M. (1999). The psychology of self-affirmation: Sustaining the integrity of the self. In R. F. Baumeister (Ed.), The self in social psychology. Key reading in social psychology (pp. 372-390). Philadelphia, PA: Psychology Press.

Tajfel, H., \& Turner, J. C. (1979). An integrative theory of intergroup conflict. In W. G. Austin \& S. Worchel (Eds.), The social psychology of intergroup relations (pp. 33-48). Monterey, CA: Brooks/Cole.

Tajfel, H., \& Turner, J. C. (1986). The social identity theory of intergroup behavior. In S. Worchel \& W. Austin (Eds.), Psychology of intergroup relations (2nd ed., pp. 7-24). Chicago, IL: Nelson-Hall.

Townshend, J. M., \& Duka, T. (2002). Patterns of alcohol drinking in a population of young social drinkers : A comparison of questionnaire and diary mesures. Alcohol and Alcoholism, 37(2), 187-192. doi:10.1093/alcalc/37.2.187

Turner, J. C., Hogg, M. A., Oakes, P. J., Reicher, S. D., \& Wetherell, M. S. (1987). Rediscovering the social group: A self-categorization theory. Oxford, UK: Blackwell. 
Van Koningsbruggen, G. M., Das, E., \& Roskos-Ewoldsen, D. R. (2009). How selfaffirmation reduces defensive processing of threatening health information: Evidence at the implicit level. Health Psychology, 28(5), 563-568. doi:10.1037/a0015610

Wakslak, C. J., \& Trope, Y. (2009). Cognitive consequences of affirming the self: The relationship between self-affirmation and object construal. Journal of Experimental Social Psychology, 45(4), 927-932. doi:10.1016/j.jesp.2009.05.002

Wechsler, H., Nelson, T. F., Lee, J. E., Seibring, M., Lewis, C., \& Keeling, R. P. (2003). Perception and reality: A national evaluation of social norms marketing interventions to reduce college students' heavy alcohol use. Journal of Studies on Alcohol, 64(4), 484494.

Wellen, J. M., \& Neale, M. (2006). Deviance, self-typicality, and group cohesion. The corrosive effects of the bad apples on the barrel. Small Group Research, 37(2), 165-186. doi:10.1177/1046-496406286420

URL: http://mc.manuscriptcentral.com/psai Email: reviews@psypress.co.uk 
Footnotes

${ }^{1}$ According to the French Observatory of Drugs and Addictions (Spilka, Le Nézet, \& Tovar, 2012), binge drinking has been increasing among French 17-year-olds (45.8\% in 2005, $48.7 \%$ in 2008 and $53.2 \%$ in 2011). Furthermore, unlike other countries (e.g., the UK), binge drinking in France affects more men (59.7\%) than women (46.5\%). In another recent national survey among 20- to 25-year-olds (Richard et al., 2013), women reported experiencing less drunkenness (33.5\%) during the previous year than men (57.4\%). 
Figure 1

Acceptance as a function of normative information and attribute affirmation (experiment 1).

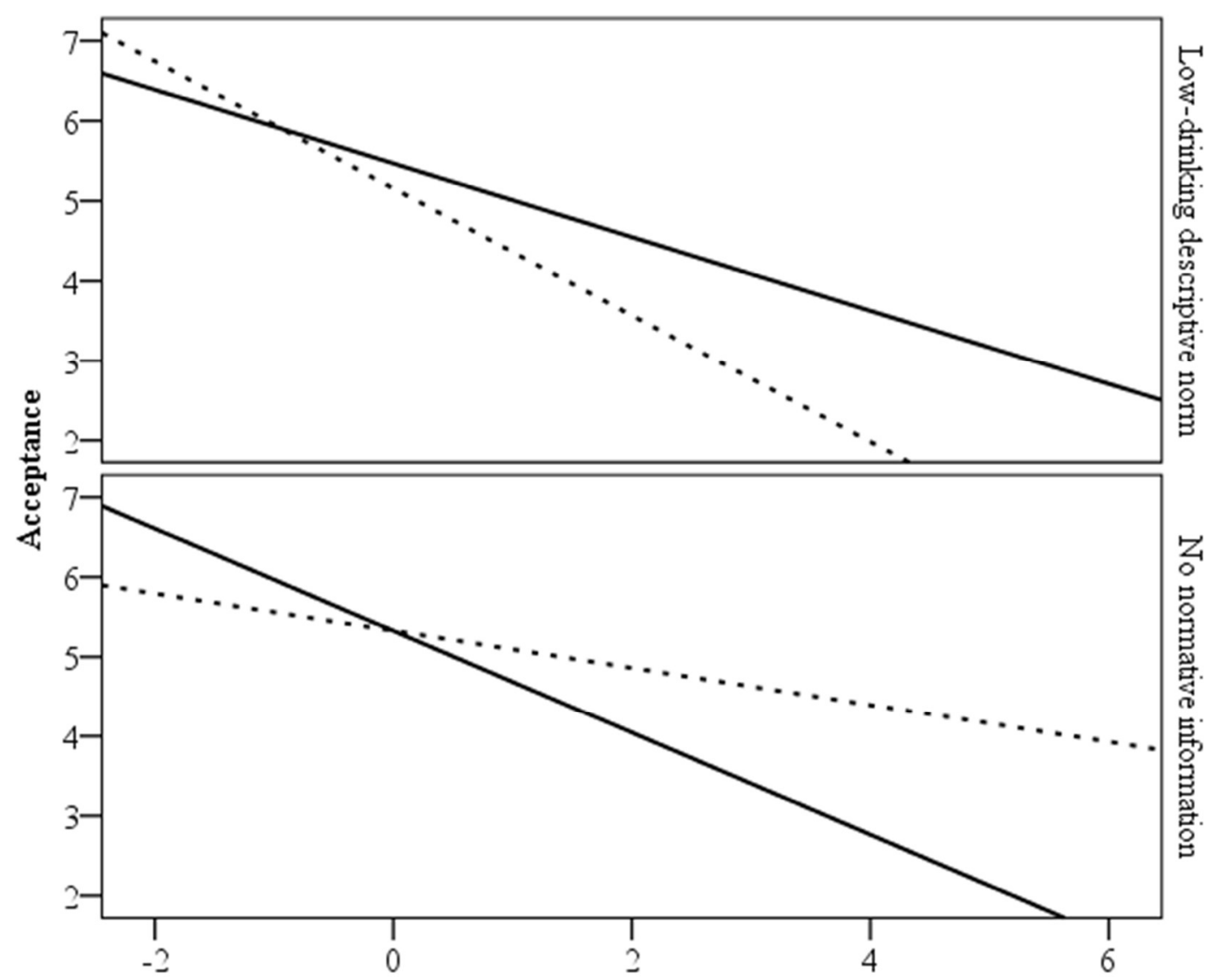

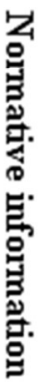

Alcohol comsumption

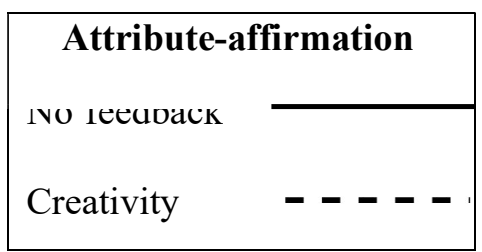

URL: http://mc.manuscriptcentral.com/psai Email: reviews@psypress.co.uk 
Figure 2

Acceptance as a function of normative information and value affirmation (experiment 2)

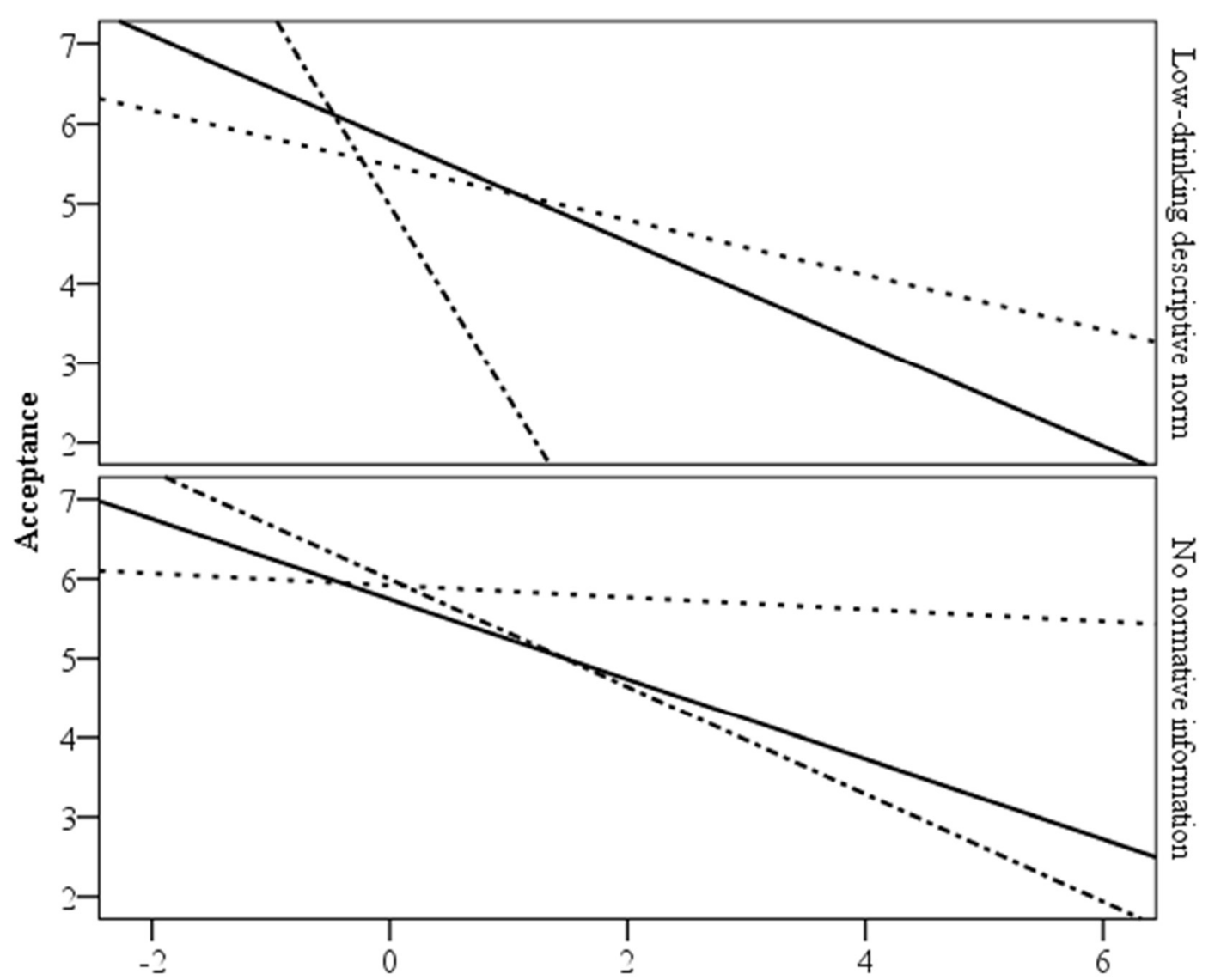

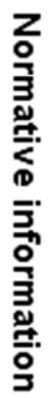

Alcohol consumption

\begin{tabular}{|c|c|}
\hline \multicolumn{2}{|c|}{ Affirmation } \\
\hline INU AIIIIIIalIOII & \\
\hline Self-affirmation & ------- \\
\hline Group-affirmation & $=-------$ \\
\hline
\end{tabular}

URL: http://mc.manuscriptcentral.com/psai Email: reviews@psypress.co.uk 


\section{Figure 3}

Mediation of the self-clarity concept between the alcohol consumption and socialization (Experiment 3).

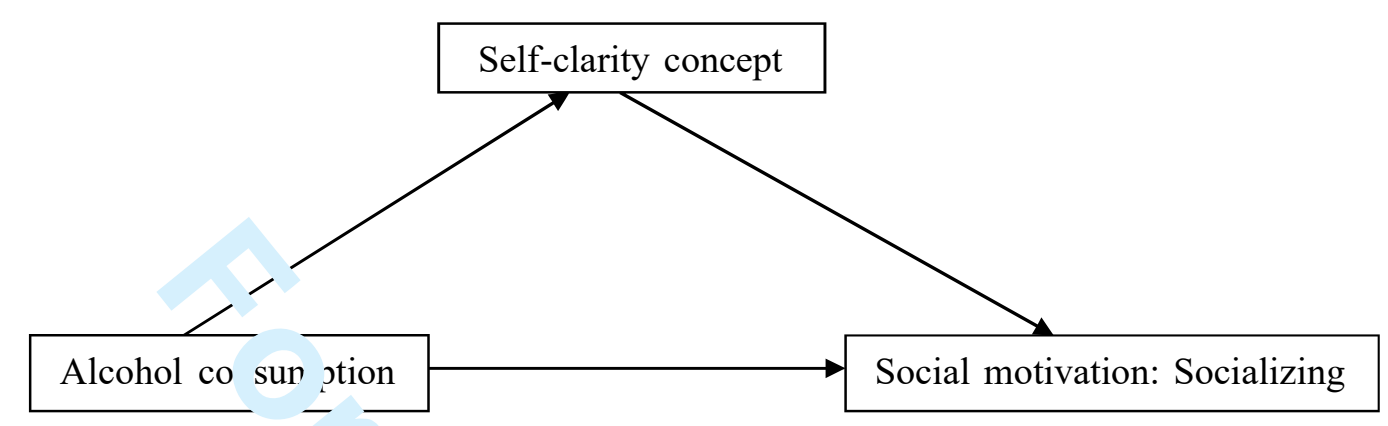

URL: http://mc.manuscriptcentral.com/psai Email: reviews@psypress.co.uk 
Table 1

Hierarchical regression of drinking behavior on acceptance as a function of normative feedback and self-affirmation.

\begin{tabular}{|c|c|c|c|c|c|c|c|}
\hline & & \multicolumn{3}{|c|}{$\begin{array}{c}\text { Model without } \\
\text { subjective norm as } \\
\text { covariate }\end{array}$} & \multicolumn{3}{|c|}{$\begin{array}{l}\text { Model with subjective } \\
\text { norm as covariate }\end{array}$} \\
\hline & $\begin{array}{l}\text { Independent variables } \\
\text { and interactions terms }\end{array}$ & $\beta$ & $t$ & $p$ & $\beta$ & $t$ & $p$ \\
\hline \multirow[t]{5}{*}{ Step 1} & Constant & & 4.05 & $<.001$ & & 5,44 & $<.001$ \\
\hline & Subjective norm & - & - & - & -.29 & -3.84 & .000 \\
\hline & Sex & -.19 & -2.33 & .021 &,- 16 & $-2,10$ &, 038 \\
\hline & Age & .11 & 1.34 & .183 &, 09 & 1,18 & ,242 \\
\hline & Lag & .07 & .84 & .401 & ,06 &, 76 &, 446 \\
\hline \multirow[t]{3}{*}{ Step 2} & $\mathrm{AC}$ & -.34 & -4.58 & $<.001$ & -.28 & -3.59 & $<.001$ \\
\hline & SA & -.08 & -1.14 & .257 & -.08 & -1.16 & .248 \\
\hline & NI & .01 & .16 & .870 & .022 & .31 & .756 \\
\hline \multirow[t]{3}{*}{ Step 3} & $\mathrm{SA} \times \mathrm{NI}$ & .08 & 1.03 & .304 & .07 & 1.03 & .304 \\
\hline & $\mathrm{AC} \times \mathrm{SA}$ & .02 & .23 & .818 & .01 & .17 & .866 \\
\hline & $\mathrm{AC} \times \mathrm{NI}$ & -.20 & -2.76 & .007 & -.18 & -2.51 & .013 \\
\hline Step 4 & $\mathrm{AC} \times \mathrm{NI} \times \mathrm{SA}$ & -.15 & -2.00 & .051 & -.12 & -1.51 & .134 \\
\hline
\end{tabular}

$\mathrm{AC}=$ Alcohol comsumption $; \mathrm{SA}=$ Self-affirmation; $\mathrm{NI}=$ Normative Information 
Table 2

Hierarchical regression of subjective norm on acceptance as a function of normative feedback and self-affirmation.

\begin{tabular}{|cl|ccc|ccc|}
\hline & & \multicolumn{3}{|c|}{$\begin{array}{c}\text { Model without subjective } \\
\text { norm }\end{array}$} & \multicolumn{2}{c|}{$\begin{array}{c}\text { Model } \text { with subjective } \\
\text { norm as covariate }\end{array}$} \\
\hline & $\begin{array}{l}\text { Independent variables } \\
\text { and interactions terms }\end{array}$ & $\beta$ & $t$ & $p$ & $\beta$ & $t$ & $p$ \\
\hline Step 1 & Constant & & 4.05 & $<.001$ & & 4.42 & $<.001$ \\
& AC & - & - & - & -.33 & -4.51 & $<.001$ \\
& Sex & -.19 & -2.33 & .021 &,- 13 & -1.72 & .088 \\
& Age & .11 & 1.34 & .183 & .09 & 1.15 & .251 \\
& Lag & .07 & .84 & .401 & .10 & 1.41 & .162 \\
\hline Step 2 & Subjective norm (SN) & -.29 & -3.85 & -000 & -.20 & -2.66 & .009 \\
& Self-affirmation (SA) & -.06 & -.84 & .400 & -.08 & -1.16 & .248 \\
& NI & .02 & .30 & .768 & .02 & .31 & .756 \\
\hline Step 3 & SA $\times$ NI & .07 & .95 & .343 & .08 & 1.08 & .280 \\
& SN $\times$ NI & -.09 & -1.25 & .214 & -.08 & -1.12 & .265 \\
& SN $\times$ SA & .18 & 2.41 & .017 & .15 & 2.03 & .045 \\
\hline Step 4 & SN $\times$ NI $\times$ SA & -.07 & -.98 & .330 & -.04 & -.52 & .601 \\
\hline
\end{tabular}

$\mathrm{AC}=$ Alcohol consomption $; \mathrm{SN}=$ Subjective norm ; SA $=$ Self-affirmation; NI = Normative Information 


\section{Appendix 1}

Two studies (one from California and one from Belgium) of young volunteers show that binge drinking causes brain damage. The Belgian researchers from the Catholic University of Louvain and the Free University of Brussels found that the students who participated actively in student night life (drinking at a party at least once per week) for nine months showed a reduction in brain activity.

The American study suggests that binge drinking causes irreversible damage to the white matter of the brain, which is responsible for the transmission of information in intellectual functioning (the study showed that the links were altered between neurons in different parts of the brain and this explained the reduction in brain activity). The lesions in the white matter, found in young people who had experienced binge drinking several times, were the same type as found in alcoholics.

These results suggest that occasional binge drinking could have the same consequences on the brain as frequent drinking. 